\title{
A Sensorimotor Pathway via Higher-Order Thalamus
}

\author{
(DChristina Mo and $\mathbb{C}$ S. Murray Sherman \\ Department of Neurobiology, University of Chicago, Chicago, Illinois 60637
}

We now know that sensory processing in cortex occurs not only via direct communication between primary to secondary areas, but also via their parallel cortico-thalamo-cortical (i.e., trans-thalamic) pathways. Both corticocortical and trans-thalamic pathways mainly signal through glutamatergic class 1 (driver) synapses, which have robust and efficient synaptic dynamics suited for the transfer of information such as receptive field properties, suggesting the importance of class 1 synapses in feedforward, hierarchical processing. However, such a parallel arrangement has only been identified in sensory cortical areas: visual, somatosensory, and auditory. To test the generality of trans-thalamic pathways, we sought to establish its presence beyond purely sensory cortices to determine whether there is a trans-thalamic pathway parallel to the established primary somatosensory (S1) to primary motor (M1) pathway. We used transsynaptic viral tracing, optogenetics in slice preparations, and bouton size analysis in the mouse (both sexes) to document that a circuit exists from layer 5 of $\mathrm{S} 1$ through the posterior medial nucleus of the thalamus to M1 with glutamatergic class 1 properties. This represents a hitherto unknown, robust sensorimotor linkage and suggests that the arrangement of parallel direct and trans-thalamic corticocortical circuits may be present as a general feature of cortical functioning.

Key words: driver pathway; motor cortex; posterior medial nucleus; sensorimotor; somatosensory cortex; trans-thalamic

\section{Significance Statement}

During sensory processing, feedforward pathways carry information such as receptive field properties via glutamatergic class 1 synapses, which have robust and efficient synaptic dynamics. As expected, class 1 synapses subserve the feedforward projection from primary to secondary sensory cortex, but also a route through specific higher-order thalamic nuclei, creating a parallel feedforward trans-thalamic pathway. We now extend the concept of cortical areas being connected via parallel, direct, and trans-thalamic circuits from purely sensory cortices to a sensorimotor cortical circuit (i.e., primary sensory cortex to primary motor cortex). This suggests a generalized arrangement for corticocortical communication.

\section{Introduction}

The classification of thalamic relays into first and higher order represents an important advance in our understanding of cortical functioning. First-order nuclei such as the lateral geniculate nucleus relay information from a subcortical source such as the retina. Conversely, higher-order nuclei such as most of the pulvinar relay information between cortical areas such as primary to secondary visual areas (V1 to V2), representing a trans-thalamic, corticocortical circuit (Sherman and Guillery, 2013; Sherman, 2016). Furthermore, where these trans-thalamic pathways have been identified, they are arranged in parallel with direct, feedforward corticocortical pathways (for review, see Sherman and Guil-

Received June 9, 2018; revised Nov. 2, 2018; accepted Nov. 24, 2018.

Author contributions: C.M. wrote the first draft of the paper; C.M. and S.M.S. edited the paper; C.M. and S.M.S. designed research; C.M. performed research; C.M. and S.M.S. analyzed data; C.M. and S.M.S. wrote the paper.

This work was supported by the National Institutes of Health (Grants NS094184 and EY022388 to S.M.S.) and the National Health and Medical Research Council of Australia (Grant 1106370 to C.M.).

The authors declare no competing financial interests.

Correspondence should be addressed to S. Murray Sherman at msherman@bsd.uchicago.edu.

https://doi.org/10.1523/JNEUROSCI.1467-18.2018

Copyright $\odot 2019$ the authors $\quad 0270-6474 / 19 / 390692-13 \$ 15.00 / 0$ lery, 2013; Sherman, 2016). Such a parallel arrangement has also been seen for the primary to secondary somatosensory areas (S1 to S2), involving the posterior medial thalamic nucleus (POm) (Theyel et al., 2010), as well as for the analogous auditory areas (A1 to A2), involving the dorsal division of the medial geniculate nucleus (for review, see Sherman and Guillery, 2013).

Another feature of the trans-thalamic pathways so far identified is that they involve class 1 glutamatergic synapses at both the corticothalamic and thalamocortical junctures. Class 1 (or "driver") glutamatergic synapses are thought to be critical in efficiently relaying information because of their large, depressing EPSCs, activation of ionotropic but not metabotropic glutamate receptors (iGluRs and mGluRs), and large and small presynaptic terminations that contact proximal dendrites. Conversely, class 2 (or "modulator") glutamatergic synapses are thought to play a modulatory role and show smaller, facilitating EPSCs, the activation of both iGluRs and mGluRs, and exclusively small bouton terminations that converge onto more distal dendrites (Sherman and Guillery, 2013; Sherman, 2016). Importantly, class 1 synapses are found in feedforward projections in sensory systems such as those carrying receptive field properties (for review, see 
Sherman, 2016). For example, in the mouse somatosensory system, the feedforward projections carrying whisker information from the principal nucleus of the fifth nerve (PrV) to the ventral posterior nucleus (VPm) to S1 and S1 to M1 are all mediated by class 1 synapses (Viaene et al., 2011a,b; Petrof et al., 2015; Mo et al., 2017). The presence of class 1 synapses in trans-thalamic pathways suggests that they are also well suited to carry basic information between cortical areas.

This arrangement of feedforward signaling via trans-thalamic pathways suggests a dramatic revision in our appreciation of corticocortical communication. However, examples of such transthalamic pathways so far have been limited to the early sensory cortices noted above. Are such trans-thalamic pathways a more general feature of cortical organization? To begin to address this, we used trans-synaptic tracing and optogenetics in slice preparations of mice to determine whether a trans-thalamic pathway exists from S1 to M1 through POm. The direct projection from S1 to M1 (Porter and White, 1983; Rocco and Brumberg, 2007; Rocco-Donovan et al., 2011; Petrof et al., 2015) is regarded as a feedforward sensorimotor circuit in rodents based on their sequential activation to a whisker stimulus (Ferezou et al., 2007). We found not only that an S1 to M1 trans-thalamic pathway exists but also that it involves exclusively class 1 synapses, mirroring the case of the direct S1 to M1 projection (Petrof et al., 2015). We suggest that this constitutes a heretofore unrecognized parallel feedforward sensorimotor circuit important for somatomotor processing. More generally, this also suggests that corticocortical circuitry involving higher-order thalamic nuclei may be a general feature of cortical processing beyond sensory areas.

\section{Materials and Methods}

Mice. All experiments were performed in accordance with protocols approved by the Institutional Animal Care and Use Committee at the University of Chicago. Transgenic mice were bred in house by crossing male $\mathrm{Tg}$ (Rbp4-cre) KL100GSat/Mmcd mice (GENSAT RP24-285K21) with female C57BL6J mice. Tail biopsies of heterozygous Rbp4-Cre mice were taken at $10-17 \mathrm{~d}$ of age and genotyped by real-time PCR (Transnetyx). Those used in experiments were a balanced mixture of male and female. All wild-type mice used in experiments were female C57BL6J (HarlanEnvigo). Mice were maintained on a $12 \mathrm{~h} \mathrm{light/dark} \mathrm{cycle} \mathrm{with} \mathrm{food} \mathrm{and}$ water available ad libutum.

Virus preparations. For the trans-synaptic tracing experiments, rAAV2retro-CAG-Cre (Tervo et al., 2016) and rAAV8-CAG-FLEx ${ }^{\text {LoxP }}$-G were sourced from the University of North Carolina at Chapel Hill (UNC) Vector Core. The titers were $8.0 \times 10^{12}$ and $1.4-2.5 \times 10^{12}$ viral particles per milliliter (vp/ml), respectively. rAAV5-CAG-FLEx ${ }^{\text {LoxP }}$-TVAmCherry at a titer of $4.7-5.5 \times 10^{12} \mathrm{vp} / \mathrm{ml}$ was custom made by the same vector core from a plasmid gifted by Liqun Luo (Addgene plasmid \# 48332; Schwarz et al., 2015). CAV2-CMV-Cre was sourced from Eric J Kremer (Montpellier Vectorology, Institut de Génétique Moléculaire de Montpellier; Soudais et al., 2001) at a titer of $6.6 \times 10^{12} \mathrm{vp} / \mathrm{ml}$. EnvApseudotyped, G-deleted rabies virus (CVS N2c strain) tagged with GFP (EnvA-RVdG-GFP) was a generous gift from the Center for Neuroanatomy with Neurotropic Viruses (Reardon et al., 2016) at a titer of 4.0$5.0 \times 10^{9}$ infectious units per milliliter.

For the electrophysiology and bouton labeling experiments, AAV5EF1a-DIO-hChR2(H134R)-eYFP-WPRE-pA and AAV5-hSyn-hChR2 (H134R)-eYFP-WPRE-pA were both sourced from UNC Vector Core at $4.4-7.0 \times 10^{12} \mathrm{vp} / \mathrm{ml}$ and $4.6-6.5 \times 10^{12} \mathrm{vp} / \mathrm{ml}$, respectively.

Tracer and viral injections. All injections were performed in the right hemisphere at a rate of $10-19 \mathrm{nl} / \mathrm{min}$. For pseudotyped rabies virusmediated tracing, 9-week-old wild-type mice were injected with 60-100 nl of a 1:1 mixture of AAV-CAG-FLEx ${ }^{\text {LoxP }}-$ G and AAV-CAG-FLEx ${ }^{\text {LoxP }}$ TVA-mCherry in POm (DV: -3.1 , ML: +1.3 , AP: $-1.4 \mathrm{~mm}$ relative to bregma) and $200 \mathrm{nl}$ of either CAV2-Cre or AAV2-retro-Cre in M1 (DV: -0.5 , ML: +0.95 , AP: $+1.45 \mathrm{~mm}$ ). After 2 weeks, the same mice were injected with 70-250 $\mathrm{nl}$ of EnvA-RVdG-GFP in POm. Transport time for $\mathrm{RVdG}$ was $4 \mathrm{~d}$ ( $n=5$ mice) or $8 \mathrm{~d}(n=4$ mice). Mice were then perfused for histological processing (described below). Nine mice were injected but two mice that underwent CAV2-Cre injections and $4 \mathrm{~d}$ of transport time for RVdG yielded very low input:starter ratios (0.016 and 0.008) and $100 \%$ of the input cells in both these mice were found in S1, skewing the data. We therefore excluded these mice, resulting in the seven animals represented in Figure 1. Of these, CAV2-Cre was injected in mice represented in the figure by $\downarrow, \star, \square$, and $\boldsymbol{\square}$ and AAV2-retro-Cre in the remaining mice. The RVdG-GFP transport time was $4 \mathrm{~d}$ in the mice represented by $\star$, and $\square$ and $8 \mathrm{~d}$ in the remaining mice. In addition, five control mice underwent the same treatment but Cre injections were omitted. EnvA-RVdG-GFP transport time was $4 \mathrm{~d}$ for 2 of these control mice, $8 \mathrm{~d}$ for the other 3 mice.

For electrophysiology experiments in Rbp4-Cre mice, 17- to 23-d-old mice were injected with AAV-DIO-ChR2-eYFP (440 nl) in S1 (DV: -0.5 , ML: +3.1, AP: -0.7$)$. Two weeks later, $370 \mathrm{nl}$ of $5 \%$ tetramethylrhodamine (10,000 MW; Thermo Fisher Scientific) in PBS was injected in M1 (DV: -0.5 , ML: +1.0, AP: +1.4). Tetramethylrhodamine (FluoroRuby) filled cell bodies and some dendrites without affecting cellular recordings (Wang et al., 2007; Schofield, 2008). After an additional 5-7 d for Fluoro-Ruby transport, mice were culled for slice electrophysiology.

To activate POm projections to M1 cells, 15- to 22-d-old wild-type mice were injected with AAV5-hSyn-ChR2-eYFP (175 nl) in POm (DV: -3.1 , ML: +1.3 , AP: -1.3 ). For control experiments to activate the S1 projection to VPm, a separate batch of mice at the same age were injected with $440 \mathrm{nl}$ of AAV5-hSyn-ChR2-eYFP in S1. For bouton size experiments, terminals in $\mathrm{M} 1$ and $\mathrm{S} 1$ were labeled from unilateral POm injections of AAV5-hSyn-ChR2-eYFP ( $120 \mathrm{nl}, n=2$ mice) and terminals in $\mathrm{VPm}$ and POm were labeled from a single $\mathrm{S} 1$ injection of the same virus $(400 \mathrm{nl})$. Transport time was 3 weeks for all AAV5-hSyn-ChR2-eYFP injections.

Surgical procedures. Mice were anesthetized with a ketamine (100 mg/ $\mathrm{kg}) / \mathrm{xylazine}(3 \mathrm{mg} / \mathrm{kg}$, i.p) mixture and secured in a stereotaxic apparatus (Kopf Instruments). Depth of anesthesia was monitored throughout by response to toe pinch and supplemental doses were administered as required. Using aseptic technique, a small burr hole was made over the target site and tracer or virus was pressure injected using a 0.5 or $1 \mu \mathrm{l}$ Hamilton syringe. For POm injections, the syringe was advanced $0.5 \mathrm{~mm}$ deeper before retracting to the target dorsoventral coordinate. After infusion, the syringe was left in place for $10 \mathrm{~min}$ before withdrawing in increments $(0.5 \mathrm{~mm} / 5 \mathrm{~min})$ to reduce upward suction of the virus. Following the injections, animals were treated locally with lidocaine hydrochloride (Akorn) and vetropolycin antibiotic ointment (Dechra). Analgesia (meloxicam, 1-2 mg/kg, s.c.) was administered preoperatively and $24 \mathrm{~h}$ postoperatively.

Slice preparation. Mice were heavily anesthetized to be nonresponsive to toe pinch and transcardially perfused with $5 \mathrm{ml}$ of cold oxygenated $\left(95 \% \mathrm{O}_{2}, 5 \% \mathrm{CO}_{2}\right)$ artificial CSF (ACSF) containing the following (in mm): $125 \mathrm{NaCl}, 25 \mathrm{NaHCO}_{3}, 3 \mathrm{KCl}, 1.25 \mathrm{NaH}_{2} \mathrm{PO}_{4}, 1 \mathrm{MgCl}_{2}, 2 \mathrm{CaCl}_{2}$, and 25 glucose. The brain was rapidly dissected, glue-mounted on a vibratome platform (Leica), and sliced in cold $\left(1-4^{\circ} \mathrm{C}\right)$, oxygenated slicing solution containing the following (in $\mathrm{mm}$ ): $2.5 \mathrm{KCl}, 1.25 \mathrm{NaH}_{2} \mathrm{PO}_{4}$, $10 \mathrm{MgSO}_{4}, 0.5 \mathrm{CaCl}_{2}, 25 \mathrm{NaHCO}_{3}, 11$ glucose, and 206 sucrose. For POm slices, brains were cut $410 \mu \mathrm{m}$ thick at $55^{\circ}$ from the midline and $10^{\circ}$ from the horizontal to preserve thalamocortical projections (Agmon and Connors, 1991). For M1 slices, brains were cut $410 \mu \mathrm{m}$ thick coronally. Brain slices were then transferred to a vessel of continuously oxygenated ACSF, which sat in a $32^{\circ} \mathrm{C}$ water bath that was then allowed to reach room temperature thereafter. Recovery in ACSF occurred in the dark for at least $2 \mathrm{~h}$ and all slicing and patching were performed at minimal light levels. Tissue containing the viral injection sites were also sliced, collected, and placed in $4 \%$ paraformaldehyde for histological processing.

Patch electrophysiology. Slices containing POm or M1 were targeted for whole-cell recordings using a visualized setup under a differential interference contrast-equipped Axioskop 2FS microscope (Carl Zeiss) and Multiclamp 700B amplifier and pCLAMP software (Molecular Devices). The expected viral expression was confirmed in each slice using the $5 \times$ air objective with a FITC filter (set 37; Zeiss) and Fluoro-Ruby-labeled 
POm cells were identified under $40 \times$ magnification with a rhodamine filter (set 15; Zeiss). Recording glass pipettes with 4-7 M $\Omega$ resistance were filled with intracellular solution containing the following (in $\mathrm{mM}$ ): 117 K-gluconate, $13 \mathrm{KCl}, 1 \mathrm{MgCl}_{2}, 0.07 \mathrm{CaCl}_{2}, 10 \mathrm{HEPES}, 0.1$ EGTA, 2 $\mathrm{Na}_{2}$-ATP, 0.4 Na-GTP, pH 7.3, 290 mOsm, and 0.5-1 dinitrostilbene2,2-disulfonic acid (a GABA $\mathrm{A}_{\mathrm{A}}$ antagonist).

To test for paired-pulse responses, four 2-ms-long laser pulses at $10 \mathrm{~Hz}$ were delivered using a $355 \mathrm{~nm}$ beam (DPSS Laser). The position of the laser beam was controlled with galvanometer mirrors (Cambridge Technology) focused on the slice through a $5 \times$ air objective using custom software in MATLAB (MathWorks). The intensity at the slice could be varied by a neutral density filter wheel before it reached the galvanometers. At a typically used intensity for activation, the beam produced an $\sim 80$ - $\mu \mathrm{m}$-diameter visible spot with a power of $5 \mathrm{~mW}$ measured at the focal plane of the slice using an optical power meter (Thorlabs), corresponding to an irradiance of $995 \mathrm{~mW} / \mathrm{mm}^{2}$. Laser activation spots were directed either over the patched cell to activate the ChR2-expressing presynaptic boutons or at a distance of $>0.32 \mathrm{~mm}$ away to activate the ChR2-expressing presynaptic axons. We chose this distance because POm and M1 dendritic arbors rarely span $>0.25 \mathrm{~mm}$ away from the cell body (Lam and Sherman, 2011; Komulainen et al., 2014), so laser activation of the patched cell at a further distance must be via presynaptic axons. When possible for the projection from $\mathrm{S} 1$ to POm, the corticothalamic fibers to the recorded cells were also electrically activated at the internal capsule by a $2 \times 1$ matrix tungsten bipolar electrode with 115 $\mu \mathrm{m}$ separation (FHC). Four 0.1-ms-long pulses were delivered at $10 \mathrm{~Hz}$. Because electrical stimulation of corticothalamic fibers captures both class 1 driver and class 2 modulator synaptic responses (layer 5 and layer 6 projections from cortex, respectively), the intensity of stimulation was initially high to elicit a mixed paired-pulse response and then lowered to just above suprathreshold to reveal the paired-pulse depression of class 1 inputs (Viaene et al., 2011b). This is due to the characteristic graded property of class 2 inputs that are thus less responsive to intensities close to threshold.

All traces illustrated are averages of two to 10 trials (typically four). The paired-pulse ratio was calculated by dividing the amplitude of the second pulse by that of the first pulse. The locations of each patched cell within M1 was photographed and later assigned to a layer by distance from pia and white matter.

Tissue processing and microscopy. Mice were transcardially perfused with PBS, pH 7.4, followed by $4 \%$ paraformaldehyde (PFA) in PBS, pH 7.4. The brain was extracted and postfixed in $4 \%$ PFA for at least $12 \mathrm{~h}$ before transferring to a cold $25 \%$ sucrose solution for $>48 \mathrm{~h}$. Brains were then cryosectioned coronally at $40 \mu \mathrm{m}$ thick on a sliding microtome. For the piece of brain tissue collected during slice electrophysiology experiments containing the M1 injection site, coronal sections were cut by supporting the tissue with a $35^{\circ}$ midline angled wedge of frozen TissueTek optimum cutting temperature medium.

Brain sections were mounted on Superfrost Plus (Fisher Scientific) slides and coverslipped with DPX or Vectashield with DAPI (Vector Laboratories). A microscope with a $100 \mathrm{~W}$ mercury lamp with fluorescence optics (Leica Microsystems) was used to image the sections and photos were taken with a Retiga 2000 monochrome CCD camera and Q Capture Pro software (QImaging).

Leica TX2 filter cubes (excitation $560 \mathrm{~nm}$, emission $645 \mathrm{~nm}$, dichroic $595 \mathrm{~nm}$ ) were used to visualize Fluoro-Ruby and mCherry fluorescence, L5 filter cubes (excitation $480 \mathrm{~nm}$, emission $527 \mathrm{~nm}$, dichroic $505 \mathrm{~nm}$ ) were used to visualize GFP and eYPF fluorescence and A4 filter cubes (excitation $360 \mathrm{~nm}$, emission $470 \mathrm{~nm}$, dichroic $400 \mathrm{~nm}$ ) to visualize DAPI fluorescence. Q Capture Pro software was used to adjust brightness and contrast of individual photos and to overlay fluorescence images. High-resolution photomicrographs of input cells and boutons were captured with LAS AF Leica software on a Leica SP5 Tandem Scanner Spectral 2-phtoon confocal microscope.

Trans-synaptic tracing analysis. For trans-synaptic tracing analyses, consecutive sections of the entire brain were mounted and analyzed. Starter cells were defined as those with clearly visible cell bodies expressing both GFP and mCherry. Starter cells were identified in photos taken with the $10 \times$ objective by overlaying GFP and mCherry images and starter cells were marked on the $2.5 \times$ objective L5 filter image of the same section. This $2.5 \times$ image was then overlaid to fit over Allen Mouse Brain Atlas images (http://www.brain-map.org) using landmarks to identify the borders of brain regions. The number of starter cells in each brain region was determined manually.

Input cells were defined as GFP-tagged cells $>500 \mu \mathrm{m}$ away from the injection site and were manually counted throughout each brain section (Wall et al., 2010; Schwarz et al., 2015) and overlaid over the brain atlas images to identify the location of input cells. The assignment to cortical layer was based on DAPI counterstaining and cortical depth. The input cells per brain region were calculated as a proportion of total input cells in each mouse. CorelDraw X4 (Corel) was used for the analysis and production of all figures. GraphPad Prism version 7.02 was used in the production of all graphs.

Bouton sizes. Injections and histological processing was as described above in previous sections except the brain slice thickness for bouton analysis was $35 \mu \mathrm{m}$. Epifluorescence photomicrographs of terminal boutons were visualized using L5 filter cubes on Q Capture Pro software and captured under the $100 \times$ oil objective with immersion oil (type A and B; Cargille Laboratories).

To analyze a representative sample of boutons across multiple sections of the brain, the $100 \times$ photos were taken at one location per section in a high-density area of terminal label. For M1 bouton analysis, the location was in layer 4; for S1 bouton analysis, the location was in layer 5A. Sequential $Z$-stack images were taken (five to 11 images per location) and the circumferences of the boutons were manually traced using Fiji ImageJ software (version 1.52a). Only boutons with a clear circumference were outlined for each image. The resolution of the digital images was $1600 \times$ 1200 pixels and the size of each pixel was $0.075 \mu \mathrm{m}$. Histograms were created with a bin width of $0.1 \mu \mathrm{m}^{2}$. Bouton sizes larger than $10 \mu \mathrm{m}^{2}$ were excluded because we attributed them to clustering rather than individual boutons ( $n=27$ excluded, all from the S1 projection to POm, although including them would not change our overall conclusions).

Experimental design and statistical analysis. All statistical analyses were conducted in GraphPad Prism version 7.02. We used the D'AgostinoPearson test to assess normality of the data and, if it was not met, nonparametric post hoc tests were used. In POm cell recordings, membrane potential and input resistance between labeled and unlabeled cells were tested using the unpaired Kolmogorov-Smirnov test. For Figure 3, analysis of the E2/E1 ratio was conducted on the cells in which data were available for both bouton and axon stimulation. A two-way repeatedmeasures ANOVA revealed a slight trend to an interaction $(p=0.094)$ but no main effects. For Figure 4, M1 cell E2/E1 ratios and EPSC response latencies were compared using the Wilcoxon matched-pairs signed-rank test. VPm cell E2/E1 ratios were tested using the nonparametric repeated-measures Freidman test, followed by Dunn's multiplecomparisons test. The first EPSC size in response to axonal stimulation in M1 and VPm cells was analyzed by the Mann-Whitney test. Differences in mean bouton size were tested using the Kruskal-Wallis test, followed by Dunn's test.

\section{Results}

We first demonstrate using anatomical techniques in the mouse that a trans-thalamic pathway from S1 to POm to M1 exists. We then use recording techniques in mouse brain slices to show that the $\mathrm{S} 1$ to $\mathrm{POm}$ and POm to M1 synapses have class 1 (driver) properties.

\section{Anatomical verification of the S1 to M1 trans-thalamic pathway via POm}

To determine whether there is a trans-thalamic pathway from $\mathrm{S} 1$ to $\mathrm{M} 1$ via POm, we used pseudotyped rabies virus to label monosynaptic inputs to the POm neurons that project to M1 (Wickersham et al., 2007; Schwarz et al., 2015). Figure 1 summarizes these results, documenting such a pathway. We first selectively targeted the POm to M1 projection using a Cre-lox strategy where canine adenovirus type-2 carrying the Cre-recombinase gene (CAV2Cre) or adeno-associated virus serotype 2 retrograde variant car- 


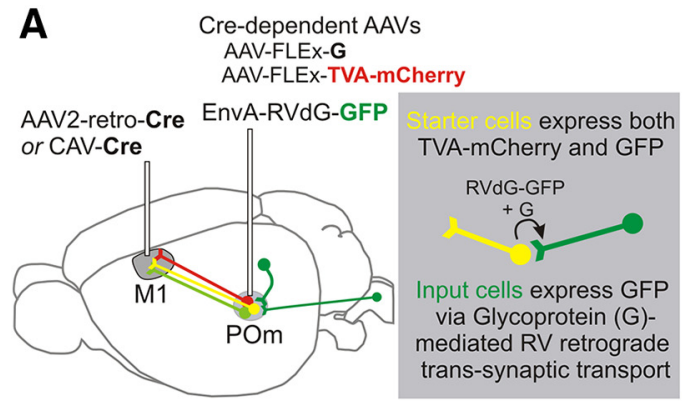

\section{Starter cell population}
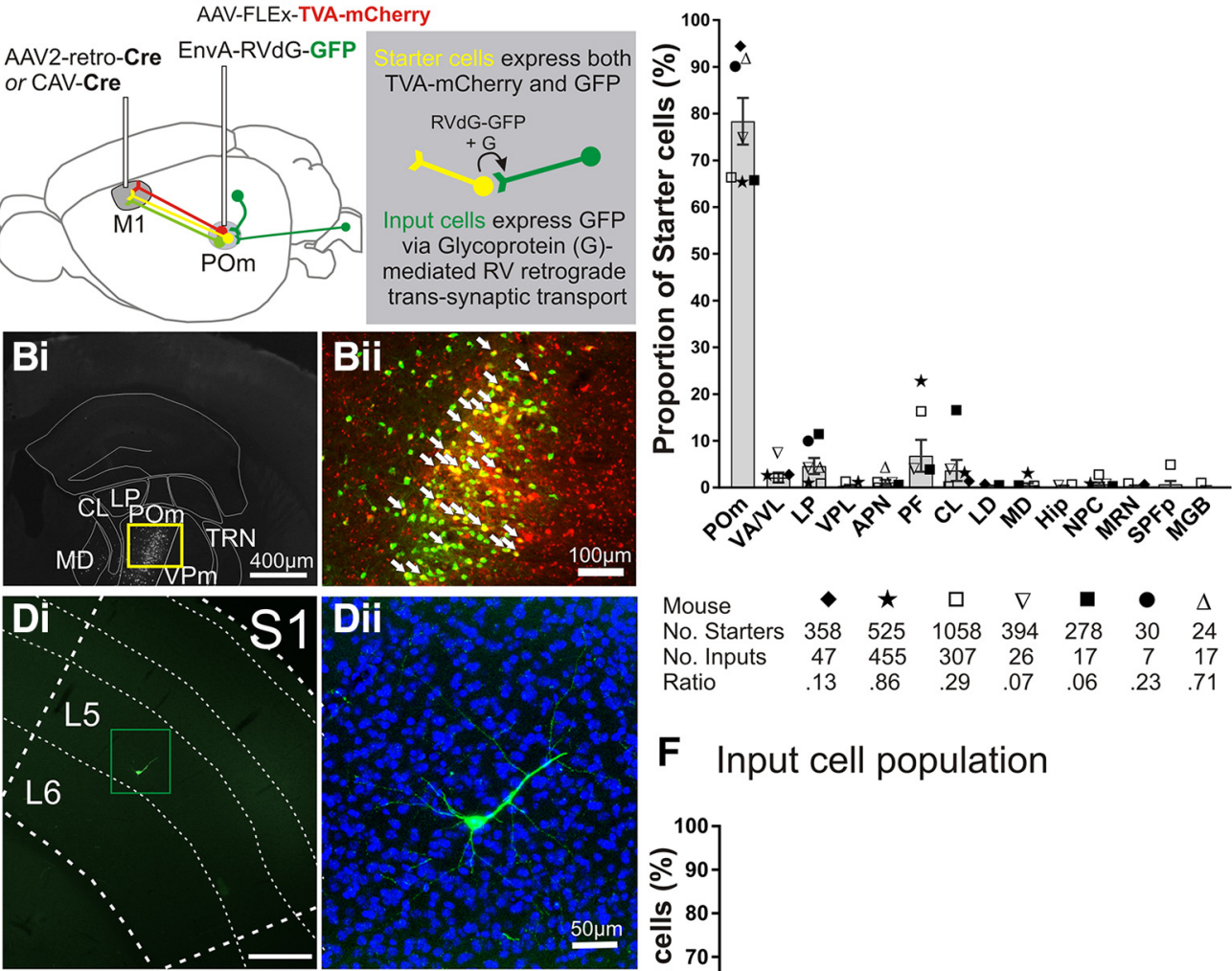

$\begin{array}{lccccccc}\text { Mouse } & \bullet & \star & \square & \nabla & \mathbf{\square} & \bullet & \Delta \\ \text { No. Starters } & 358 & 525 & 1058 & 394 & 278 & 30 & 24 \\ \text { No. Inputs } & 47 & 455 & 307 & 26 & 17 & 7 & 17 \\ \text { Ratio } & .13 & .86 & .29 & .07 & .06 & .23 & .71\end{array}$

\section{F Input cell population}
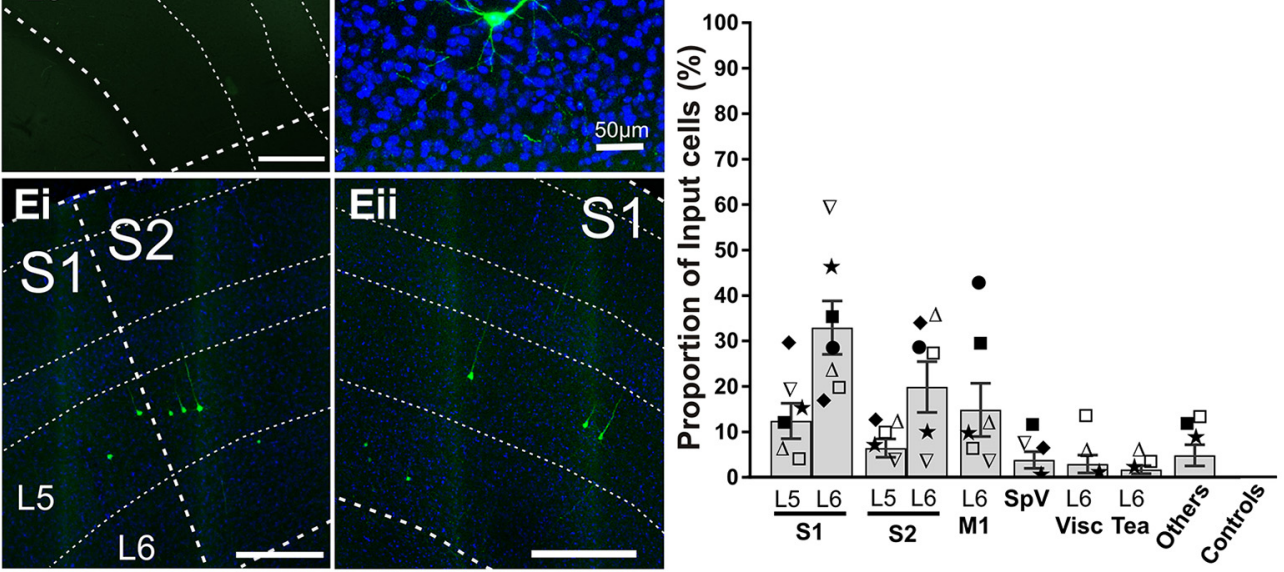

Figure 1. Trans-synaptic tracing of the inputs to the POm $\rightarrow M 1$ pathway. $A$, Schematic of pseudotyped rabies virus-based tracing to label monosynaptic inputs to POm cells projecting to $\mathrm{M} 1$. CAV-Cre or AAV2-retro-Cre injected into M1 retrogradely transports to POm where two Cre-dependent AAVs are injected, AAV-CAG-FLEx ${ }^{\text {LoxP }}$-TVA-mCherry and AAV-CAG-FLEX ${ }^{\text {LoxP }}$-G. Therefore, M1-projecting POm cells are the only cells that can express the TVA receptor, which is recognized by the ligand EnvA, and glycoprotein (G), the envelope protein required retrograde trans-transport of rabies virus. Two weeks later, EnvA-pseudotyped, G-deleted rabies virus tagged with GFP (EnvA-RVdG-GFP) is injected into POm (green projections). Starter cells (yellow projections) are those expressing both TVA-mCherry and GFP. After an additional $4-8 \mathrm{~d}$, starter cells that also express glycoprotein $\mathrm{G}$ allow the RVdG-GFP to bud out of the cell and retrogradely spread across the synapse resulting in GFP expressed in the input cells (dark green projections). Therefore, input cells make direct presynaptic contact with M1-projecting POm starter cells. Bi, Representative coronal epifluorescence image of RVdG-infected GFP-expressing cells in POm. Bii, Higher magnification of yellow box in Bi showing starter cells expressing both GFP and TVA-mCherry (overlay). White arrows indicate a subset of starter cells. C, Starter cell locations as a proportion of total starter cell population for each mouse. The majority of starter cells were located in POm (78.4 $\pm 5.0 \%)$, but were also found in nuclei surrounding POm, which also project to frontal and motor areas. Each symbol represents a mouse $(n=7)$ and the total numbers of starter cells, input cells, and ratios are noted below. $\boldsymbol{D}, \boldsymbol{E}$, Representative epifluorescence images of GFP-labeled input cells in $\mathrm{S} 1$ and S2. S1 layer 5 cell from mouse $\nabla$ in $\boldsymbol{D i}$ is magnified (green box) with DAPI stain in Dii. Cells in Ei and ii are from mouse $\star$. Scale bars are $300 \mu \mathrm{m}$ unless otherwise noted. $\boldsymbol{F}$, Input cell locations as a proportion of total inputs for each mouse. Symbols correspond to those in C. Error bars indicate SEM. APN, Anterior pretectal nucleus; CL, central lateral nucleus; Hip, hippocampus; LD, lateral dorsal nucleus; MD, mediodorsal nucleus; MGB, medial geniculate nucleus, including ventral, medial, and dorsal regions; MRN, midbrain reticular nucleus; NPC, nucleus of the posterior commissure; Tea, temporal association areas; Visc, visceral area; VPL, ventral posterolateral nucleus.

rying Cre (AAV2-retro-Cre) was injected into M1 and two Credependent AAVs were injected into POm. The Cre-dependent AAVs carry either the rabies glycoprotein $(G)$ or the avian EnvA envelope receptor TVA tagged with mCherry (TVA-mCherry). The M1 and POm injections result in the expression of $\mathrm{G}$ and TVA-mCherry in POm cells that project to M1 (Fig. 1A). After 2 weeks, EnvA-pseudotyped, G-deleted rabies virus tagged with GFP (EnvA-RVdG-GFP) was injected into POm. Only cells expressing the TVA receptor can be infected with EnvA-RVdG-GFP and those cells that also express $\mathrm{G}$ on their membrane allow $\mathrm{G}+$ RVdG-GFP to bud off and spread retrogradely across the synapse. The lack of $G$ expression in the infected presynaptic cell prevents RVdG-GFP from further trans-synaptic spread.

Neurons that coexpress GFP and TVA-mCherry are termed "starter cells" (yellow cells, Fig. 1 A, Bii) because they can be the origin of retrograde trans-synaptic transport. Successful retrograde trans-synaptic spread of RVdG-GFP results in the expression of GFP in the cells presynaptic to starter cells. These cells that 
express GFP outside the injection site area are called "input cells" (Schwarz et al., 2015) (Fig. 1A).

Starter cells were identified and mapped onto the coronal Allen Mouse Brain Atlas (Fig. 1B). In 7 mice, the majority of the starter cell population was located in POm $(78.4 \pm 5.0 \%$, mean \pm SEM, percentage of total starter cells averaged across mice) (Fig. $1 C)$. However, nuclei adjacent to POm that also project to motor cortices (Hunnicutt et al., 2014) also contained small proportions of the starter population, such as the parafascicular nucleus (PF) $(6.7 \pm 3.4)$, ventral anterior/lateral nucleus (VA/VL) $(2.1 \pm 1.1)$, central lateral nucleus $(3.7 \pm 2.2)$, lateral dorsal nucleus $(0.3 \pm$ 0.1 ), and lateral posterior nucleus (LP) $(4.6 \pm 1.7)$ (Fig. $1 C)$. The targeted injection of CAV-Cre or AAV2-retro-Cre into M1 was confirmed in each mouse by locating the microsyringe injection site. However, these Cre-carrying viruses do not carry a fluorescent tag, so some spread to adjacent M2 or premotor areas may have occurred and would explain starter cell labeling in frontal cortex-projecting nuclei such as the lateral dorsal nucleus $(0.3 \pm$ $0.1)$ and mediodorsal nucleus $(0.5 \pm 0.4)$. We therefore cannot rule out that inputs to these non-POm starter cells also contribute to the total input cell population.

Across mice, the majority of input cells were found in S1 $(45.3 \pm 7.1$ percentage of input cells across mice \pm SEM $)$, followed by S2 (26. $3 \pm 6.5)$ (Fig. $1 D-F)$. Relevant to the current study is the presence of input cells in S1 layer 5 in 6 of 7 mice $(12.4 \pm 3.8)$ and in S2 layer 5 in 5 of 7 mice $(6.4 \pm 2.0)$ (Fig. $1 F$ ). Layer 6 cortical inputs to POm showed a higher proportion of the input population than that of layer 5 inputs, as expected (Sherman, 2016). This included visceral cortex layer $6(2.9 \pm 2.0)$, which sits adjacent to somatosensory cortices. M1 layer 6 was a main anatomical input to POm cells projecting to M1 (14.9 \pm 5.9), but starter cells in VA/VL, which also send reciprocal projections to M1 (Porter and White, 1983), may have contributed to M1 input labeling. The contralateral spinal nucleus of the fifth nerve $(\mathrm{SpV})$ was also identified as an input region in 3 mice $(1.4 \pm 1.2)$, suggesting a paralemniscal pathway from $\mathrm{SpV}$ to POm to M1, perhaps via branched cortical targets (Bosman et al., 2011; Ohno et al., 2012). Inputs from temporal association cortex layer $6(1.7 \pm 0.9)$ may also be expected given its known projections to POm and the medial geniculate nucleus (Vaudano et al., 1991).

Other input regions not shown in Figure $1 F$ were found in three mice. For the mouse represented by $\mathbf{\square}$, these were the globus pallidus (5.9\%) and cerebellum (5.9\%). For the mouse represented by $\star$, auditory cortex $(3.1 \%)$ and insula agranular (1.1\%) were labeled. For the mouse represented by $\square$, visceral cortex layer $5(1.0 \%)$, auditory cortex dorsal and ventral regions, layers 5 and $6(5.5 \%)$, and insula agranular cortex (2.6\%) showed input cells. Other regions that contributed to $<1 \%$ of the input population per mouse were found in the mice represented by $\star$ and $\square$ only (perirhinal cortex, claustrum, gustatory cortex, ectorhinal cortex, contralateral M1 and orbital lateral cortex). The presence of these low proportions of input areas may be partly due to the starter cell population outside of POm (Fig. 1D), such as the medial geniculate nucleus starter cells causing auditory cortex input cells.

It may also be expected that POm cells projecting to M1 (our starter cell population) receive projections from areas such as the zona incerta and thalamic reticular nucleus (Barthó et al., 2002) and we indeed saw GFP-labeled cells in the thalamic reticular nucleus (TRN), although less consistently in the zona incerta in our injected mice. However, these local regions around the POm injection site were excluded from input analysis because this method of trans-synaptic tracing can only reliably identify longrange presynaptic connections (Callaway and Luo, 2015; Schwarz et al., 2015). Control experiments omitting viral Cre delivery $(n=5$ mice) did not result in any input cells (Fig. $1 F)$, but a low number of nonspecific GFP-labeled cells were identified within $500 \mu \mathrm{m}$ of the POm injection site $(n=6-11$ per brain for $4 \mathrm{~d}$ RVdG transport, $n=11-25$ per brain for $8 \mathrm{~d}$ transport), consistent with previous reports (Schwarz et al., 2015). Without Cre recombinase, these brains should not show any expression of TVA-mCherry or GFP because TVA expression is cre dependent and EnvA-RVdG-GFP infection is dependent on TVA expression. However, low levels of RVdG-GFP are reported by us and others, possibly due to Cre-independent TVA-mCherry expression undetectable with mCherry fluorescence (referred to as "leak expression"; Miyamichi et al., 2013), combined with the very efficient interaction of the TVA receptor and its EnvA ligand. These RVdG-GFP-infected cells cannot be distinguished from trans-synaptically infected input cells, so cells proximal to the injection site are excluded from input analysis (Wall et al., 2010; Miyamichi et al., 2013; Beier et al., 2015; Callaway and Luo, 2015; Schwarz et al., 2015). In our case, we excluded the analysis of input cells within a $500 \mu \mathrm{m}$ radius of the injection site. The input population therefore ignores all potential local inputs to the POm projection to M1, but key to the current study is the identification of $\mathrm{S} 1$ layer 5 cells as presynaptic inputs to the POm to M1 projection (Fig. $1 D-F)$. These data not only confirm the existence of a trans-thalamic pathway from S1 to M1 via POm, but also that S2 projects to $\mathrm{M} 1$ via $\mathrm{POm}$.

We found the number of input cells identified per brain to be highly variable, ranging from seven to 455 cells (Fig. 1C). Others have also reported highly variable input cell populations (e.g., $n=65-5769$ input cells in Schwarz et al., 2015). Potential explanations may be topographically misaligned CAV and AAV/RVdG injections resulting in low expression and fewer starter cells or, in the cases where starter cell populations were healthy but the input populations were very low (e.g., Fig. $1 F$, mouse $\square$ : 278 starters, 17 inputs), we suspect inefficient expression of glycoprotein, which is necessary for retrograde trans-synaptic spread of the rabies virus. This virus carrying glycoprotein does not have a fluorescent tag and we could not assess its expression in each brain. We do not interpret the very low ratios of input:starter cells $(0.27 \pm$ 0.1 ) as an indicator of the amount of convergence to POm cells projecting to $\mathrm{M} 1$, but rather take the results as qualitative, establishing the presence of an S1 layer 5 projection to M1-projecting POm cells. S1 layer 5 appears to be a strong anatomical projection even when trans-synaptic tracing efficacy is low.

\section{Targeting the trans-thalamic pathway for electrophysiology}

After anatomically establishing the existence of a trans-thalamic pathway from S1 to M1, we sought to identify the nature of the synapses-class 1, class 2, or other-between S1 and POm and between POm and M1. Although trans-synaptic tracing revealed that both layer 5 and layer 6 of S1 input to POm cells projecting to M1 (Fig. 1), we focused on the layer 5 subset because it has been previously shown to provide class 1 synaptic inputs to POm cells (Reichova and Sherman, 2004) and is the hypothesized origin layer of trans-thalamic pathways (Sherman and Guillery, 2013; Sherman, 2016). We therefore used a transgenic, viral, and tracer strategy to target POm cells that project to motor areas and receive input from S1 layer 5 (Fig. 2).

To target terminals from layer 5 of S1, we injected a Credependent virus (AAV5-EF1a-DIO-ChR2-eYFP) into S1 of Rbp4Cre mice, the cortices of which express Cre recombinase in layer 

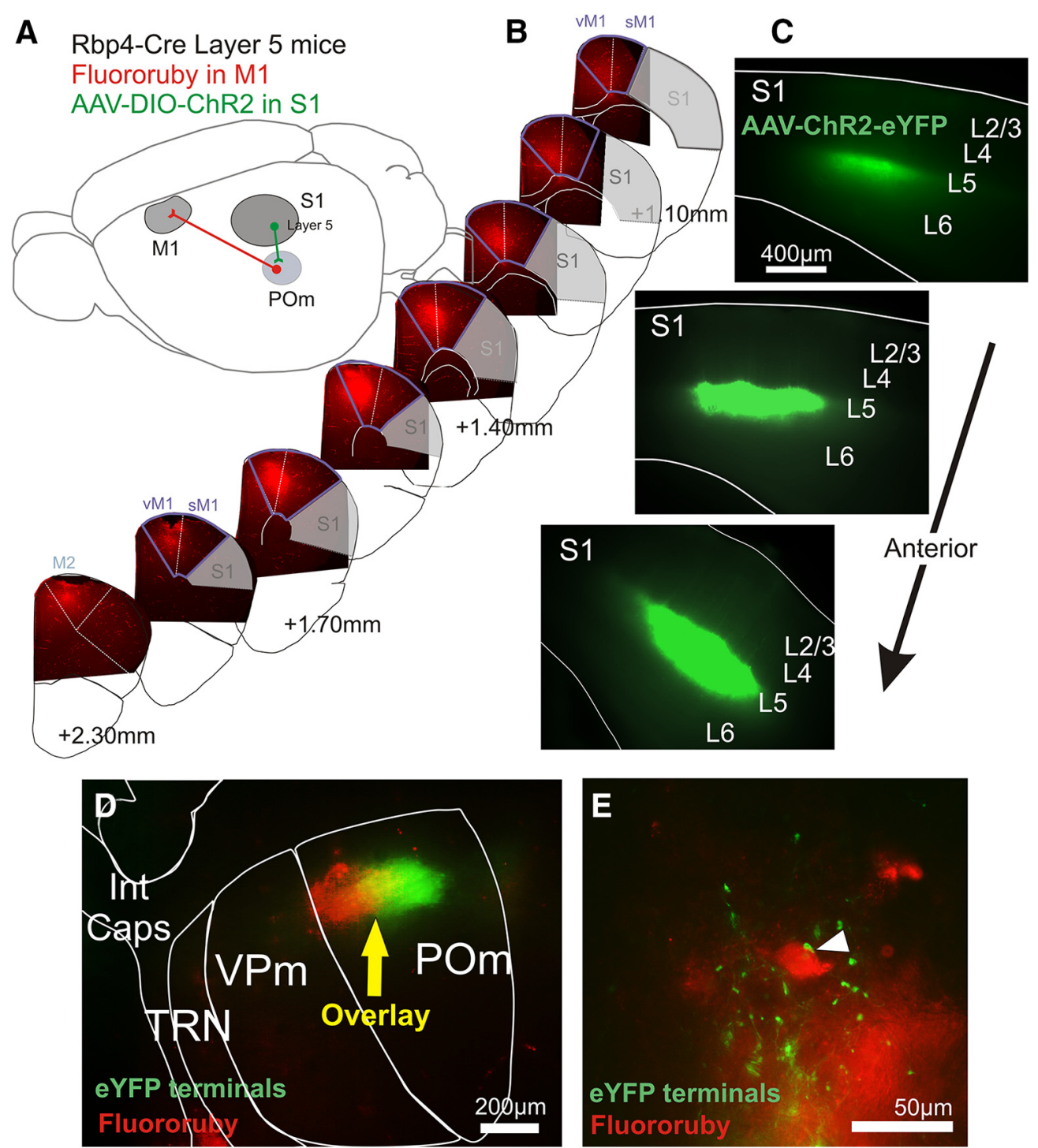

Figure 2. Targeting POm cells of the S1 to M1 trans-thalamic pathway. A, Schematic of strategy to activate $S 1$ layer 5 inputs to POm cells that project to M1. Such M1-projecting cells in P0m are retrogradely labeled for identification during recording, and a Cre transgenic line is used to express ChR2 in $\mathrm{S} 1$ layer 5 cells that project to POm cells. $\boldsymbol{B}$, Epifluorescence images of coronal 40 - $\mu \mathrm{m}$-thick sections from an example frontal area of tissue processed after electrophysiology experiments to confirm that Fluoro-Ruby expression was restricted to motor areas. The anterior-posterior positions are estimated relative to bregma. $\boldsymbol{C}$, In the same brain, images of 410- $\mu \mathrm{m}$-thick slices used for slice recording showing AAV-DI0-ChR2-eYFP expression restricted to S1 layer 5 . D, The same slice showing thalamus with transported Fluoro-Ruby label and transported S1 layer 5 eYFP label overlaid in POm. E, Epifluorescent image in POm after histological processing with AAV-ChR2-eYFP terminations proximal to Fluoro-Ruby-labeled cell bodies. Int Caps, Internal capsule; vM1, vibrissal area primary of motor cortex; sM1, somatic area of primary motor cortex.

5 (Fig. 2A). We visualized eYFP fluorescence in S1 of each mouse, confirming characteristic expression restricted to layer 5 and apical dendrites extending to layer 1 (Fig. 2C). S1 layer 5 terminals were found in Pom, but not in the adjacent VPm or the TRN (Fig. 2D), consistent with previous reports (Veinante et al., 2000). In the same S1-injected mice, we labeled POm cell bodies that project to M1 by injecting the retrograde tracer Fluoro-Ruby in M1. The M1 injection site for each brain was postprocessed to confirm that labeling was restricted to vibrissal and somatic M1 (Fig. $2 B$ ), as defined by projection patterns and stimulation-response mapping (Ferezou et al., 2007; Hooks et al., 2011). The retrograde transport of Fluoro-Ruby resulted in label in POm, which partially overlapped with S1 layer 5-labeled terminals (Fig. 2D). It was in the region of overlap (yellow zone) that we targeted our whole-cell patch recordings (indicated by yellow arrow in Fig. 2D). Separate histological processing showed ChR2-eYFP terminations proximal to Fluoro-Ruby-labeled cell bodies (Fig. 2E).

\section{Class 1 driver properties of S1 layer 5 inputs to POm cells} projecting to $\mathrm{M} 1$

In a slice that preserves corticothalamic fibers to POm, we targeted both Fluoro-Ruby-labeled and unlabeled POm cells for whole-cell patch recordings and stimulated S1 layer 5 inputs optogenetically and electrically (Fig. 3A). We recorded from a total of 70 POm cells in 29 animals located in the eYFP-Fluoro-Ruby overlap zone within POm as indicated by the example in Figure 2D. Of these, 43 cells were labeled with Fluoro-Ruby (Fig. 3Ai) and thus projected to M1. These labeled cells had an uncorrected average membrane potential of $-56.8 \pm 1.1 \mathrm{mV}$ (hereafter, this represents the mean and SEM) and an average input resistance of $115.9 \pm 4.9 \mathrm{M} \Omega$. The rest were unlabeled POm cells $(n=27)$ and showed an uncorrected average membrane potential of $-59.6 \pm$ $1.1 \mathrm{mV}$ and average input resistance of $124.3 \pm 7.6 \mathrm{M} \Omega$. There were no statistically significant differences in labeled compared with unlabeled cells in their average membrane potential $(p=$ 
A
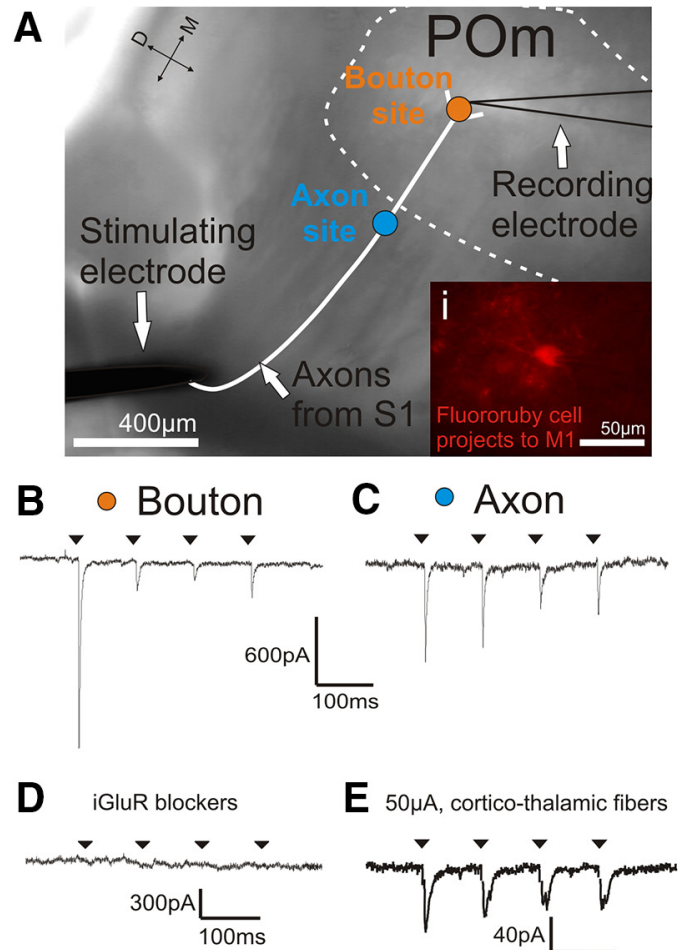

E $50 \mu \mathrm{A}$, cortico-thalamic fibers

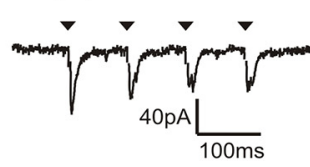

F
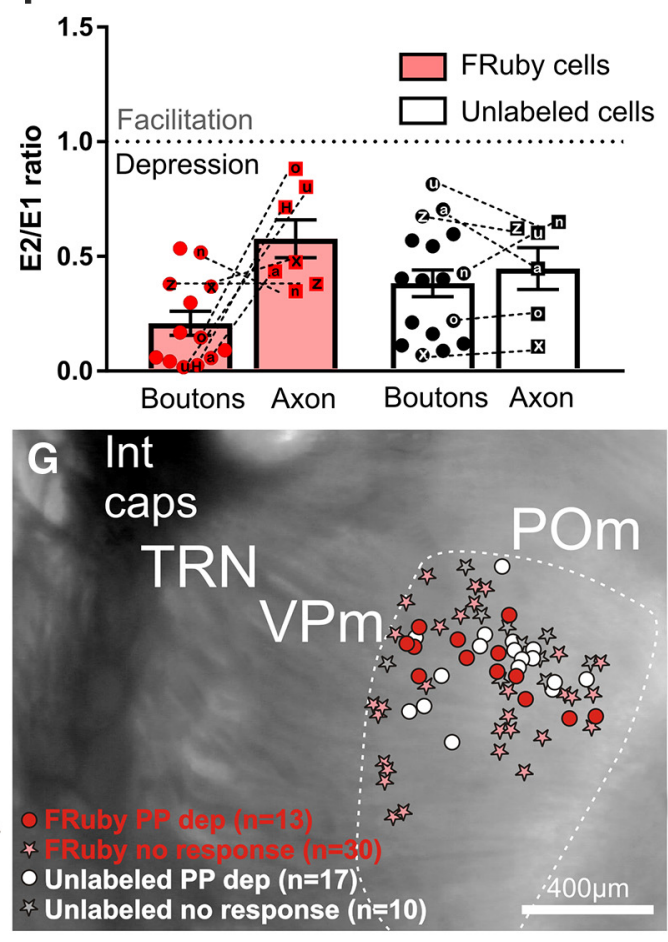

Figure 3. Class 1 (driver) synaptic responses of M1-projecting POm cells to S1 layer 5 input. $A$, Schematic of stimulation sites in relation to a recorded POm cell overlaid on a representative bright-field image of a somatosensory slice. The slice is from Rbp4-Cre mice injected with ChR2-eYFP and Fluoro-Ruby (fluorescence not shown; see Fig. 2). Three methods were used to stimulate S1 layer 5 inputs to POm cells: optogenetic activation of terminal boutons (orange dot), optogenetic activation of axons $>0.32 \mathrm{~mm}$ from the recorded cell body (blue dot), and electrical stimulation at the internal capsule (black stimulating electrode). The bottom right inset (Ai) shows a Fluoro-Ruby-labeled POm cell under a rhodamine filter during recording. $\boldsymbol{B}$ - $\boldsymbol{E}$, Example voltage-clamp recordings from the Fluoro-Ruby cell located in $\boldsymbol{A}$. $\boldsymbol{B}$, Response of the cell to stimulation of $S 1$ layer 5 boutons (orange dot in $\boldsymbol{A}$ ). $\boldsymbol{C}$, Response of the cell to axon stimulation (blue dot in $\boldsymbol{A}$ ). $\boldsymbol{D}$, Response of the cell to laser stimulation of boutons during DNQX and AP5 bath application. $\boldsymbol{E}$, Response of the cell to electrical stimulation (50 $\mu \mathrm{A})$ at the internal capsule. $\boldsymbol{F}$, Paired-pulse ratios $[($ second EPSC amplitude (E2)/first EPSC amplitude (E1)] of Fluoro-Ruby $(n=13)$ and unlabeled ( $n=17$ ) cells stimulated at the boutons or axons. A ratio of $<1$ represents paired-pulse depression and a ratio $>1$ represents facilitation. Dotted lines join data points of bouton and axon stimulations from the same cell and analyses of these paired data did not reveal any differences (two-way repeated-measures ANOVA). G, Locations of POm recorded cells (Fluoro-Ruby-labeled and nonlabeled) and their response to paired-pulse laser stimulation. No paired-pulse facilitation was observed in any case and only those cells located within an area of $\mathrm{S1}$ termination zones in POm were included. Patch locations were reconstructed from photos taken during recording, which were all compiled and overlaid on a representative slice image. Error bars indicate SEM. FRuby, Fluoro-Ruby; Int Caps, internal capsule; PP dep, paired-pulse depression.

0.16 , Kolmogorov-Smirnov test) or input resistance $(p=0.11$, Kolmogorov-Smirnov test).

Of the 43 M1-projecting Fluoro-Ruby-labeled cells, 13 (30\%) were optogenetically activated by input from S1 layer 5, which supports the anatomical data shown in Figure 1 of a transthalamic pathway from S1 layer 5 to M1 via POm. Short-term synaptic plasticity is a defining feature for distinguishing class 1 from class 2 glutamatergic synapses; paired-pulse depression seen in class 1 synapses indicates a high probability of transmitter release supporting information-bearing driver projections (for review, see Sherman and Guillery, 2013). In labeled cells, we found a consistent pattern of paired-pulse depression with optogenetic and electrical stimulation in every responsive POm cell (Fig. $3 B, C, E$ ). Our focal laser delivery, with a maximal circular size of $\sim 80 \mu \mathrm{m}$ in diameter, allowed us to differentiate optogenetic bouton versus axon stimulation, which is important when investigating paired-pulse effects via optogenetics (Jackman et al., 2014). Optogenetic $10 \mathrm{~Hz}$ laser stimulation of terminal boutons (orange dot in Fig. $3 A$ ) resulted in extremely strong pairedpulse depression (Fig. $3 B$ ), which has been reported previously in Rbp4-Cre mice in the cortico-striatal pathway (Wu et al., 2015). Stimulation of afferent axons further from the recorded cells (blue dot in Fig. 3A) also resulted in paired-pulse depression, but the depression was less profound (Fig. $3 C$ ) and its extent consistent with previous reports using electrical stimulation of the af- ferent axons (Fig. 3E) (e.g., (Reichova and Sherman, 2004). We quantified the strength of paired-pulse depression for all responsive cells by calculating the ratio between the magnitudes of the second and first evoked EPSCs (Fig. $3 F$ ). When analyzing only the cells that responded to both stimulation sites $(n=12)$, there were no significant main effects, although there was a slight trend to an interaction (two-way repeated-measures ANOVA interaction $p=0.094)$.

The laser-evoked EPSCs were eliminated after application of ionotropic glutamate receptor antagonists, indicating that the stimulation caused a glutamatergic-dependent postsynaptic response $(n=3$, Fig. $3 D)$. There was also no obvious spatial localization within POm of labeled versus unlabeled or responsive versus unresponsive cells in POm (Fig. 3G).

Previous work has identified the layer $5 \mathrm{~S} 1$ input to $\mathrm{POm}$ as class 1 (Reichova and Sherman, 2004), so we expected the pairedpulse optogenetic stimulation to result in depression. However, artifactual synaptic depression is a concern when using particular AAV serotypes (Jackman et al., 2014), so we confirmed our result using electrical stimulation. In a subset of four Fluoro-Rubylabeled POm neurons, we evoked EPSCs by electrical activation of the corticothalamic fibers passing through the internal capsule (stimulating electrode in Fig. $3 A$ ) and found that a $10 \mathrm{~Hz}$ pulse train also resulted in synaptic depression (Fig. $3 E$ ). Electrical stimulation of the internal capsule also activated the S1 layer 6 
fibers projecting to POm cells, a projection known to be class 2 modulatory. In cases where we saw evidence of mixed class 1 and 2 responses (indicating that these class 2 layer 6 projections were also activated), reducing the magnitude of the electrical stimulus to just above threshold allowed us to isolate the class 1 inputs by their all-or-none property (Viaene et al., 2011b).

Of the 43 Fluoro-Ruby-labeled cells, 30 (70\%) did not respond to optogenetic stimulation. This suggests that these M1projecting cells receive driving inputs from other than layer 5 of S1 (e.g., from another cortical area or from SpV; Mo et al., 2017), although we cannot rule out that the inputs from S1 layer 5 existed but were not activated due to inefficient AAV infection or misaligned topography of the $S 1$ and $\mathrm{M} 1$ projections to and from POm, respectively.

We also recorded from 27 unlabeled cells in the overlap zone of POm, the majority of which $(n=17$ or $63 \%)$ responded to optogenetic activation of the $S 1$ layer 5 input. The higher proportion of unlabeled cells compared with Fluoro-Ruby-labeled cells responding to S1 layer 5 input (63\% vs $29 \%$ ) is likely in part due to incomplete labeling of all M1-projecting cells by Fluoro-Ruby, but also suggests that a large proportion of S1 layer 5 input synapse onto POm cells that project to brain areas other than M1. We have documented such a circuit from S1 to S2 (Theyel et al., 2010), but the possibility exists that areas other than S2 and M1 receive trans-thalamic input via POm from $\mathrm{S} 1$. That all of the optogenetically activated unlabeled cells also exhibited pairedpulse depression in response to laser stimulation is consistent with previous results with electrical activation in the same pathway (Reichova and Sherman, 2004).

\section{POm provides class 1 input to cells in all layers of M1}

We next sought to define the synaptic properties (e.g., class 1 or 2 ) of the POm to M1 inputs. To this end, we injected AAV5-hSynChR2-eYFP in POm of wild-type mice and tested the evoked responses in $\mathrm{M} 1$ cells (Fig. 4Ai). We were able to target the POm to $\mathrm{M} 1$ projection by examining the injection site (Fig. 4Aii) and pattern of terminal expression in M1 (Fig. 4B, inset). Thalamic nuclei that also project to frontal areas including M1 are the paracentral nucleus, anteromedial nucleus, lateral dorsal nucleus, and VA/VL complex; these nuclei preferentially target layer 5B, 5A, and 2/3 of M1 (Hooks et al., 2013; Hunnicutt et al., 2014; Yamawaki et al., 2014). Conversely, POm terminations in M1 preferentially target layer $2 / 3,4$, and $5 \mathrm{~A}$ (Fig. $4 B$ ). We therefore excluded any brains with injections that resulted in layer $5 \mathrm{~B}$ terminations in M1. Three posterior-central thalamic nuclei other than POm, LP, PF, and subparafascicular nucleus (SPFp) also terminate in M1 with a pattern favoring layers 2/3 and 5A (Hunnicutt et al., 2014). Therefore, when examining the injection site for each brain, we ensured that the eYFP label was restricted to POm and VPm, avoiding the dorsally positioned LP, the medially positioned PF, and the medioventrally positioned SPFp (Fig. 4Aii). Because VPm does not project to M1 (Hooks et al., 2011, 2013; Hunnicutt et al., 2014; Yamawaki and Shepherd, 2015), optogenetic activation while recording M1 cells would only activate their POm inputs. Slices of brains with injections that had spread to nuclei other than POm and VPm were not considered further. Recordings have been pooled from a total of seven animals.

We recorded from a total of 45 cells in $\mathrm{M} 1$, which were aligned within the band of ChR2-eYFP expression (Fig. 4B). These cells showed an uncorrected average membrane potential of $-62.1 \pm$ $1.1 \mathrm{mV}$ and an average input resistance of $123.6 \pm 7.6 \mathrm{M} \Omega$. Layers in $\mathrm{M} 1$ were defined by relative cortical depth (Yamawaki et al.,
2014). Using images taken of each patch position, we post hoc assigned the cells to layer $2 / 3(n=5)$, layer $4(n=7)$, layer $5 \mathrm{~A}$ $(n=14)$, layer 5B $(n=11)$, and layer $6(n=8)$. Note that even neurons with cell bodies in layers other than those innervated by thalamocortical terminals still responded to POm input, presumably due to apical and basal dendrites extending into the terminal zones. Of the $45 \mathrm{M} 1$ cells, 41 (91\%) responded to optogenetic activation of POm terminals (Fig. $4 B$ ) and all responses were depressing to $10 \mathrm{~Hz}$ paired-pulse stimulation. This paired-pulse response was found in all cases of stimulation aimed at either POm boutons or at POm axons at least $320 \mu \mathrm{m}$ away from the recorded cell (Fig. 4C-E). Paired-pulse ratios were slightly more depressed when elicited by optogenetics at boutons compared with at axons ( $p=0.012$, Wilcoxon signed rank test; Fig. $4 E)$. A trend for the same effect was found at the S1 layer 5 to POm synapse (Fig. $3 F$ ) and has also been reported by others (Jackman et al., 2014). As expected, bouton stimulation elicited shorter EPSC response latencies than did axon stimulation (bouton, $2.4 \pm 0.14 \mathrm{~ms}$ vs axon, $3.6 \pm 0.23 \mathrm{~ms}, p<0.0001$, Wilcoxon signed-rank test). The relatively short latency of responses, particularly with bouton stimulation, combined with the fact that there are no known intrathalamic, local excitatory inputs to thalamic relay cells (e.g., from other relay cells), suggests that the responses are monosynaptic. Because axons from POm entering M1 do not form a clearly defined bundle within which we could place an electrical stimulating electrode, we were unable to complement our optogenetic results with electrical stimulation. However, the axonal optogenetic stimulation produces similar paired-pulse responses as those seen with electrical stimulation and axon-targeted activation does not seem to suffer from the artifacts of direct bouton stimulation (see Fig. $3 C$ vs $E$ and Jackman et al., 2014).

One might question whether stimulation using our excitatory opsin is capable of detecting paired-pulse facilitation, so to address this, we injected the same virus (AAV5-hSyn-ChR2-eYFP) into the S1 cortico-thalamic projection to VPm in separate experiments (Fig. 4Fi). Electrical stimulation of the S1 layer 6 to VPm synapse (class 2) is known to exclusively elicit paired-pulse facilitation (Castro-Alamancos and Calcagnotto, 1999; Reichova and Sherman, 2004; Cruikshank et al., 2010). Injections in the deep layers of S1 resulted in the expected eYFP-ChR2 labeling in TRN, VPm, and POm (Fig. 4Fii,Fiii). Whole-cell recordings from VPm ( $n=6$ cells) and focused optogenetic stimulation on the presynaptic boutons (orange dot in Fig. 4Fiii) caused synaptic depression (Fig. 4G). However, the same stimulation targeted at the presynaptic axons (blue dot in Fig. 4Fiii) elicited paired-pulse facilitation (Fig. 4H), in agreement with the expected response to electrical stimulation of S1 axons (yellow dot in Fig. 4Fiii, I). Only four of six cells responded to electrical stimulation, most likely due to severed fibers in the slice. Analyzing these four cells, we found that electrical compared with optogenetic bouton stimulation led to very different paired-pulse ratios $(p=0.014$, Dunn's test; Fig. 4J).

Our data for paired-pulse responses suggest that, for accurate paired-pulse assessments, focal laser stimulation should always occur along the presynaptic axon distant from the recorded cell, not at presynaptic terminals. In paired-pulse assessments of POm to M1 synapses, we directed optogenetic stimulation at POm axons in a subset of bouton-stimulated M1 cells ( $n=32$ of 41 cells) and found that the majority $(n=30$ cells) responded with paired-pulse depression (blue squares in Fig. $4 C$ ). For the remaining two cells, we were unable to find a response. A large proportion of patched M1 cells received inputs from POm (41 of 
A AAV-hSyn-ChR2-eYFP in POm

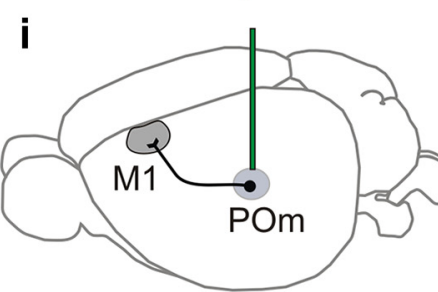

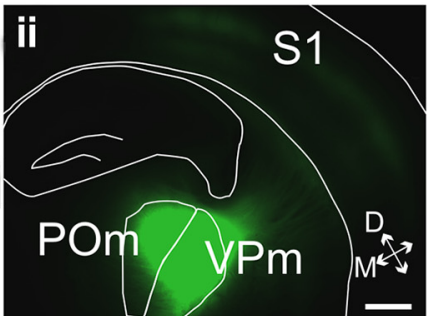

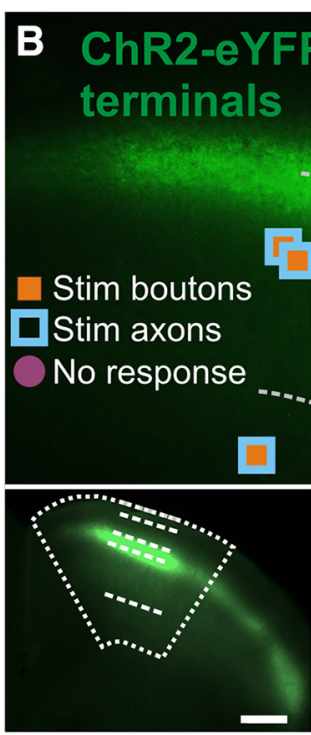

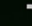
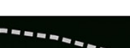

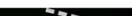
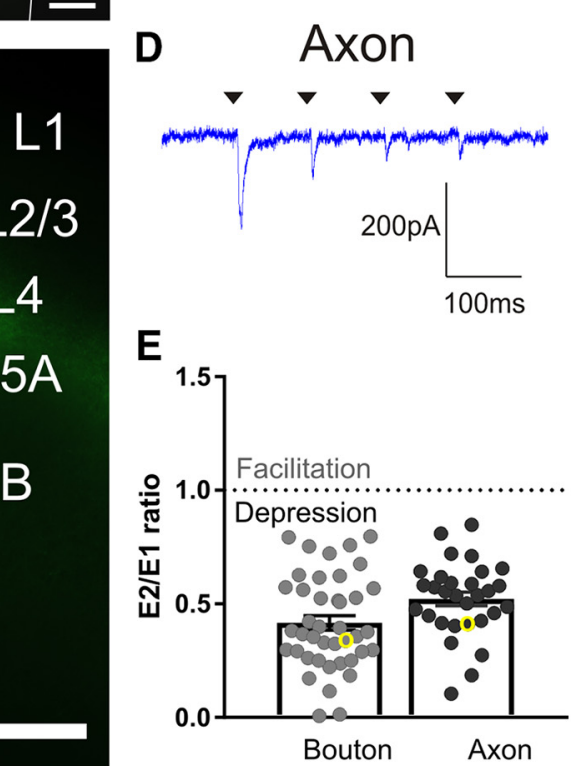

E

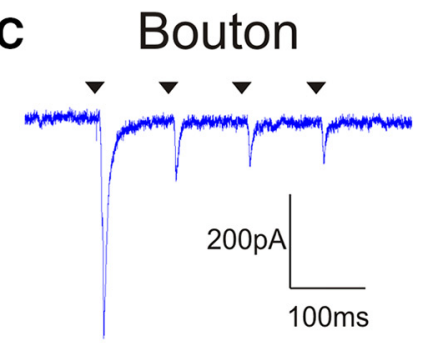

F AAV-hSyn-ChR2-eYFP in S1

i

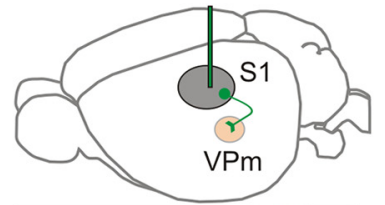

ii
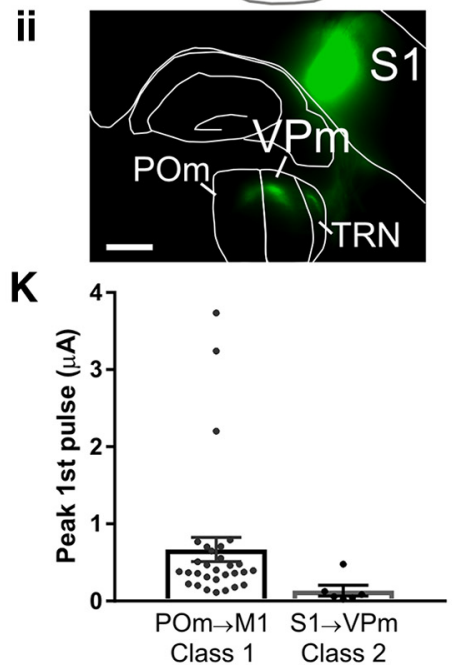
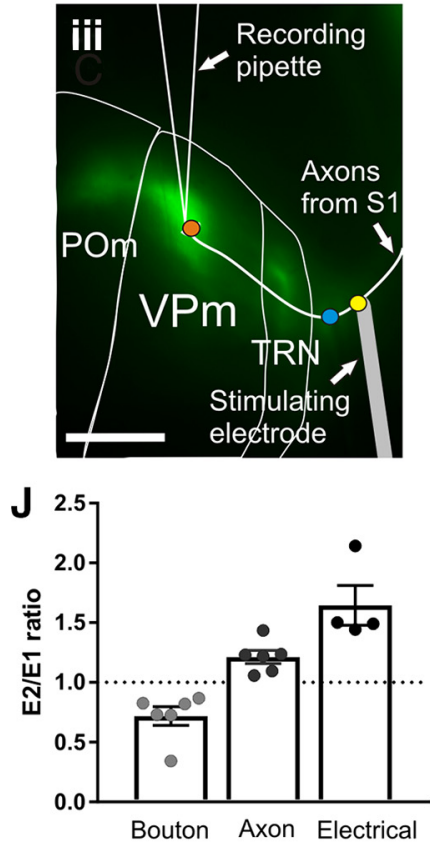

\section{G $\circ$ Bouton}

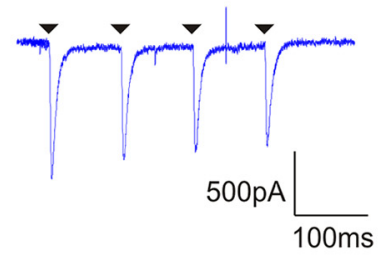

H Axon

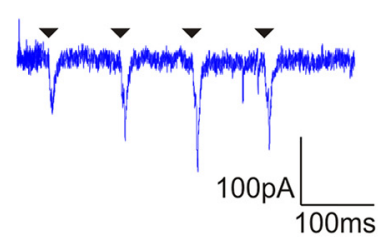

I $\circ$ Electrical

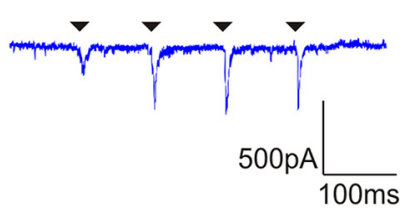

Figure 4. Class 1 synaptic responses of M1 cells in response to activation of POm inputs. Ai, Schematic of the ChR2-eYFP injection in POm to test the synaptic properties of the P0m to M1 projection. Aii, Epifluorescence image of a representative coronal slice containing the POm injection site. We aimed our injections closer to border of adjacent VPm (resulting in characteristic expression in $\mathrm{S}$ barrels) to avoid infecting medial thalamic nuclei which also project to $\mathrm{M} 1 . \boldsymbol{B}$, Relative positions of all patched $\mathrm{M} 1$ cells overlaid on a representative epifluorescence image of $\mathrm{M} 1$ with ChR2-eYFP terminal expression. Layers in M1 were defined by relative cortical depth and POm terminals showed characteristic projections to upper layers. Orange-filled squares are cells that responded with paired-pulse depression to optogenetic stimulation of boutons. Blue squared outlines are cells responded with paired-pulse depression to optogenetic axon stimulation $>0.32 \mathrm{~mm}$ from recorded cell body. All cells that received axon stimulation also received bouton stimulation. Purple-filled circles are cells with no response to optogenetic stimulation. Bottom left inset, Image of the same M1 coronal slice at a lower magnification. $\boldsymbol{C}$, Example trace for the response of a layer $4 \mathrm{M} 1$ cell (yellow arrow in $\boldsymbol{B}$ ) during four pulses of bouton laser stimulation. $\boldsymbol{D}$, Trace from the same M1 cell during axon laser stimulation. $\boldsymbol{E}$, Paired-pulse ratios of all M1 cells. The ratios from the traces in $\boldsymbol{C}$ and $\boldsymbol{D}$ are indicated by yellow circles. The response(Figure legend continues.) 
45) and all layers in M1 (excluding layer 1, in which there are few cell bodies and in which recordings were not attempted) could be strongly activated with class 1 inputs from POm.

It is important to note that our strategy to optogenetically activate the POm to M1 projection did not selectively target the S1 to M1 trans-thalamic pathway. That is, all POm cells projecting to M1 were potentially activated, not just POm cells postsynaptic to layer 5 of S1. However, because all responsive M1 cells showed class 1 properties and most responded to POm stimulation, it seems highly likely that at least some of these M1 cells were targets of the S1 to M1 trans-thalamic pathway.

The size of the EPSC is characteristically larger in class 1 synapses compared with class 2 (Sherman and Guillery, 2013). We therefore analyzed the first EPSC evoked by axonal optogenetic stimulation in S1 to VPm synapse (class 2) compared with the POm to M1 synapse (Fig. $4 K$ ). The EPSCs were much larger in the POm to M1 pathway ( $p=0.002$, Mann-Whitney test), suggesting greater neurotransmitter release.

\section{Bouton size analysis}

The size of presynaptic terminals has also been used to help classify a synapse as class 1 or class 2 (Sherman and Guillery, 2013; Sherman, 2016). Class 2 modulatory synapses are composed of small presynaptic terminations and class 1 driver synapses are composed of both large and small terminations (Li et al., 2003; Viaene et al., 2011a,b; Petrof and Sherman, 2013; Petrof et al., 2015; Mo et al., 2017). We injected the same eYFP-tagged AAV used in the electrophysiology experiments (Fig. 4) and measured the area of boutons in the POm to M1 synapse, comparing it with bouton sizes of synapses previously classified as class 1 or class 2: S1 to VPm (class 2), POm to S1 layer 5 (class 2), and S1 to POm (both class 1 and 2) (Viaene et al., 2011a; Petrof et al., 2015; Mo and Sherman, 2017; Fig. 5).

Data from M1 and S1 were compiled from POm injections in $n=2$ mice and the terminations in VPm and POm were labeled from the same $\mathrm{S} 1$ injection (Fig. $5 A-C$ ). Compared with previous data using biotinylated dextran amine (BDA) to label boutons in VPm, S1, and POm (Viaene et al., 2011a; Petrof et al., 2015; Mo and Sherman, 2017), we calculated similar means but a larger range of bouton sizes (mean range using AAV: $0.50-2.28 \mu \mathrm{m}^{2}$ vs mean range of BDA studies: $0.71-1.25 \mu \mathrm{m}^{2}$ ). It should be noted that the $S 1$ injection was largely concentrated in layer 5 compared with layer 6 (Fig. 5B), resulting in a denser labeling of class 1

$\leftarrow$

(Figure legend continued.) to optogenetic bouton stimulation was smaller compared with axon stimulation ( $p=0.012$, Wilcoxon test). A ratio of $<1$ represents paired-pulse depression and a ratio $>1$ represents facilitation. Fi, Schematic of the strategy to express ChR2-eYFP in the S1 layer 6 projection to VPm. Fii, Epifluorescence image of an example somatosensory slice showing the $\mathrm{S} 1$ injection site and the eYFP-labeled terminals in TRN, VPm, and POm. S1 projections to TRN and VPm arise only from layer 6 . The imaged slice was $410 \mu \mathrm{m}$ thick and viewed under the $L 5$ filter after cell recordings were completed. Fiii, View of the same example slice depicting the relative locations of the three stimulation sites during recording of a VPm cell: optogenetic stimulation of terminal boutons (orange dot), optogenetic stimulation of axons (blue dot), and electrical stimulation at the internal capsule (yellow dot). $\mathbf{G}$, Response of the VPm cell shown in Fiiii to four pulses at the bouton (orange dot in Fiii). $\boldsymbol{H}$, Response of the same cell showing paired-pulse facilitation to optogenetic axon stimulation (blue dot in Fiii). I, Response of the same cell showing paired-pulse facilitation to electrical stimulation at the internal capsule (150 $\mu \mathrm{A}$; yellow dot in Fiiii). J, Paired-pulse ratios of VPm cells responding to bouton, axon, and electrical stimulation. Optogenetic bouton stimulation elicited a strong depression compared with electrical stimulation of the axon for the same cell ( $p=0.014$, Dunn's test). $\boldsymbol{K}$, Maximum amplitudes of the first pulse during optogenetic axon stimulation for the two synapses tested. The EPSPs from the POm to M1 synapse were larger than the S1 to VPm class 2 synapse ( $p=0.0019$, Mann-Whitney test). All scale bars are $200 \mu \mathrm{m}$. Error bars indicate SEM. synapses in POm (Fig. 5Bii), even though $\mathrm{S} 1$ to POm is a mixture of class 1 (from layer 5) and class 2 (from layer 6).

We measured the cross-sectional area of 1380 boutons in the POm to M1 pathway, 963 boutons in POm to S1 layer 5A pathway, 1150 boutons in S1 to POm pathway, and 963 boutons in S1 to VPm pathway. Data confirmed that synapses with purely class 2 terminations consisted of smaller bouton sizes (POm to $\mathrm{S} 1_{\mathrm{L} 5 \mathrm{~A}}$ mean $=0.54 \pm 0.01 \mu \mathrm{m}^{2}$ and S1 to VPm mean $=0.50 \pm 0.01$ $\mu \mathrm{m}^{2}$ ) compared with synapses with mixed class 1 and class 2 inputs $\left(\mathrm{S} 1\right.$ to $\mathrm{POm}$ mean $\left.=2.28 \pm 0.07 \mu \mathrm{m}^{2}\right)\left(\mathrm{POm}\right.$ to $\mathrm{S} 1_{\mathrm{L} 5 \mathrm{~A}}$ vs S1 to POm and S1 to VPm vs S1 to POm, Dunn's test, $p<0.0001$ for both comparisons).

POm to M1 bouton sizes $\left(\right.$ mean $=0.98 \pm 0.02 \mu \mathrm{m}^{2}$ ) were larger than class 2 boutons (POm to $\mathrm{S} 1_{\mathrm{L} 5 \mathrm{~A}}$ and $\mathrm{S} 1$ to $\mathrm{VPm}$ ) and, on average, smaller than the mixed class 1 and 2 boutons of the $S 1$ to POm corticothalamic synapse (Dunn's test, $p<0.0001$ for all comparisons). However, the much higher mean bouton size of the $\mathrm{S} 1$ to POm synapse is due to a proportion of very large boutons (as reported previously in Mo et al., 2017). This is depicted in the extensive tail of the histogram plot (red line in Fig. 5D). In the thalamocortical POm to S2 synapse, which is class 1 , the mean bouton size $\left(0.98 \pm 0.47 \mu \mathrm{m}^{2}\right)$ (Viaene et al., 2011a) is very similar to that of the POm to M1 synapse that we report here $\left(0.98 \pm 0.02 \mu \mathrm{m}^{2}\right)$.

Consistent with previous reports, we found that class 2 synapses comprise small boutons and class 1 synapses comprise both large and small boutons, the synapse of POm to M1 being consistent with the latter. We confirmed previous reports that $\mathrm{S} 1$ to POm also consists of large and small boutons (Fig. 5; also (Liao et al., 2010; Mo et al., 2017)). Therefore, bouton size analyses support that the two synapses in the trans-thalamic pathway from S1 layer 5 to POm to M1 are exclusively class 1 synapses.

\section{Discussion}

We used anatomical and physiological approaches to document the presence of a robust trans-thalamic pathway from S1 through POm to M1, highlighting a previously unknown feedforward circuit. This is organized in parallel to a direct S1 to M1 pathway previously documented (Porter and White, 1983; Rocco and Brumberg, 2007; Rocco-Donovan et al., 2011; Petrof et al., 2015). Such an arrangement of direct and trans-thalamic pathways has been demonstrated for the sensory pathways involving visual, auditory, and somatosensory cortices. This is the first evidence that it applies to a sensorimotor circuit, supporting the idea that parallel trans-thalamic pathways are a general organizing principle of cortex.

\section{Newly identified class 1 sensorimotor linkage}

Trans-synaptic tracing was used to report monosynaptic connections between the S1 layer 5 projection to POm (Veinante et al., 2000; Reichova and Sherman, 2004) and the POm projection to M1 (Miyashita et al., 1994; Deschênes et al., 1998; Ohno et al., 2012; Hooks et al., 2013). We then identified properties of the synapses that suggest that this trans-thalamic pathway is a robust and efficient information route. Glutamatergic pathways in thalamus and cortex can be classified into two functionally distinct types, which we refer to here as class 1 ("driver") and class 2 ("modulator"). Class 1 inputs evoke strong postsynaptic responses with a high probability of transmitter release and have been associated with carrying the main information between neurons, whereas class 2 inputs provide a more subtle function, like classical modulators (e.g., cholinergic, serotonergic, etc.), affecting how driver inputs are processed (Sherman and Guillery, 

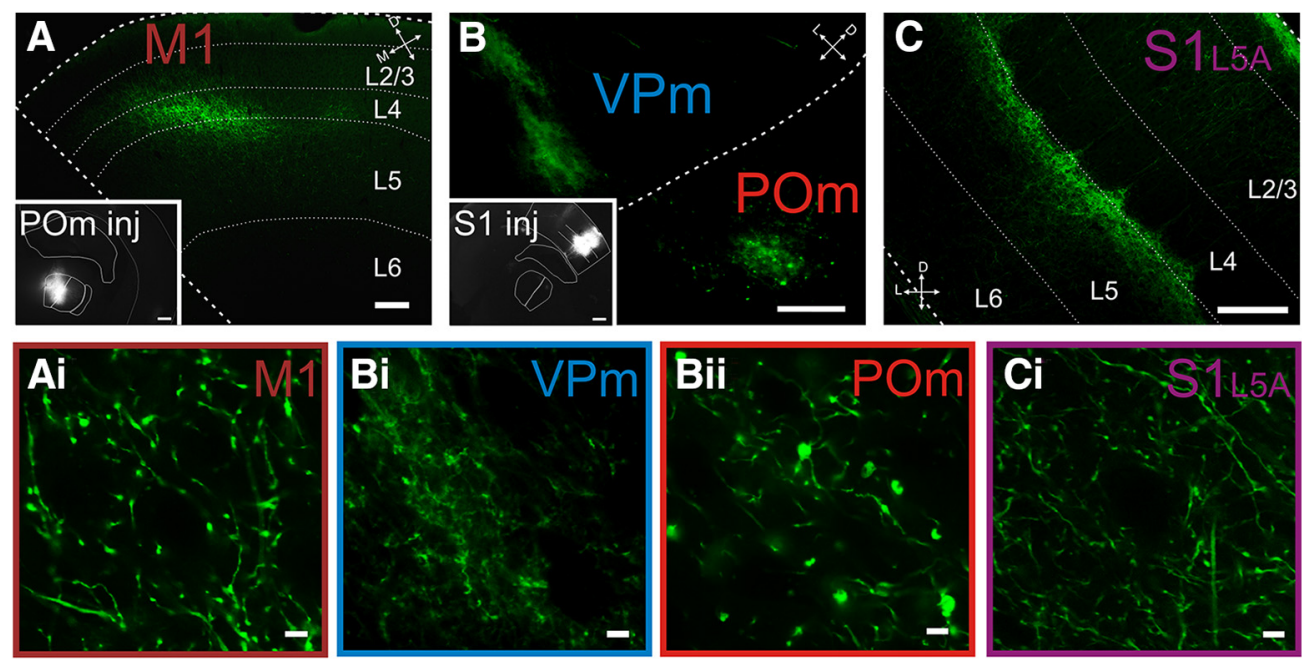

D

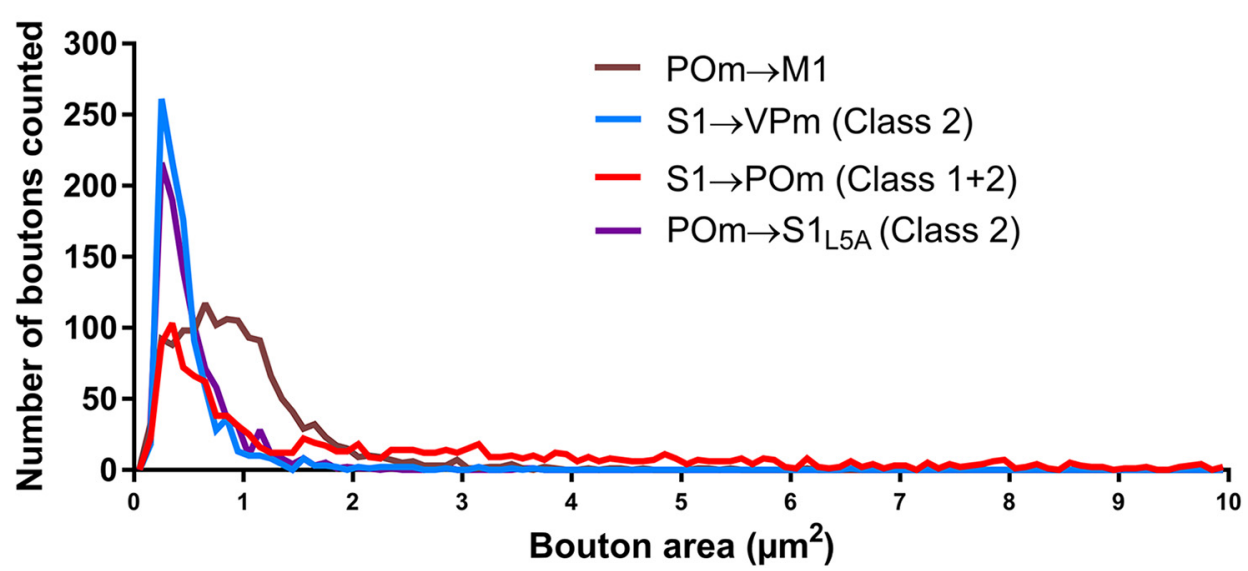

Figure 5. Terminal sizes in the POm to M1 projection indicate a class 1 synapse. $\boldsymbol{A}-\boldsymbol{C}$, Epifluorescence images of AAV-hSyn-ChR2-eYFP terminations in the P0m to M1 projection (A) the 51 to VPm (class 2) and POm projections (class 1 and 2) (B) and the POm to 51 projection (class 2) (C). Insets show the corresponding injection sites. Note the higher level of expression of AAV in layer 5 compared with layer 6 of $S 1$ (B, inset). The $S 1$ photo shown in $($ shared the same injection as in $\boldsymbol{A}$. $\mathbf{A i}-\boldsymbol{C} \boldsymbol{C}$, Representative photomicrographs at high magnification of boutons from the corresponding photos in $\boldsymbol{A}-\boldsymbol{C}$. $\boldsymbol{D}$, Histograms of bouton area per projection illustrating that class 1 synapses have a longer distribution in the upper range of bouton sizes, whereas class 2 synapses show a distribution restricted to smaller bouton sizes. Scale bars: $\boldsymbol{A}-\boldsymbol{C}, 100 \mu \mathrm{m} ; \boldsymbol{A}$ and $\boldsymbol{B}$ insets, $400 \mu \mathrm{m} ; \boldsymbol{A i}, \boldsymbol{B i}, \boldsymbol{B i i}$, and $\boldsymbol{C} \boldsymbol{i}, 5 \mu \mathrm{m}$.

2013; Sherman, 2016). In sensory systems, class 1 synapses exist along the feedforward route encoding receptive field properties, between primary and secondary cortex, and also in the parallel route through higher-order thalamus. For example, in a somatosensory slice, S1 could robustly activate S2 via POm independently of the direct $S 1$ to $S 2$ circuit (Theyel et al., 2010). The direct S1 to M1 pathway is entirely class 1 (Petrof et al., 2015) and we demonstrate here that the parallel trans-thalamic pathway between these areas is also composed of class 1 inputs both at the corticothalamic (S1 layer 5 to POm; see also Reichova and Sherman, 2004) and thalamocortical (POm to M1) synapses.

The characteristic properties of class 1 synapses are large, depressing EPSCs, the presence of iGluRs but absence of mGluRs, and both large and small presynaptic boutons (for review, see Sherman and Guillery, 2013). For the S1 layer 5 projection to POm, we found large, depressing EPSCs and large and small boutons, which confirms its class 1 properties (Reichova and Sherman, 2004) and also specifies this feature for those POm cells that project to M1 (Fig. 3). The POm to M1 synaptic properties had not yet been investigated. We showed that the first EPSC was large compared with a class 2 EPSC (Fig. $4 K$ ), that optogenetic stimulation led to a depressing EPSC response (Fig. $4 E$ ), and that the presynaptic boutons are both large and small (Fig. 5). We were unable to assess the presence of mGluRs in this pathway because this requires high-frequency stimulation of M1-projecting fibers to elicit a metabotropic response, which is unachievable by the opsins that we used for optogenetic activation. Electrical stimulation was also not possible because a brain slice cannot selectively capture the fiber tract from POm to M1. However, paired-pulse depression, especially when considered with large first EPSP amplitudes, is sufficient to identify class 1 synapses between thalamus and cortex (see Fig. $2 B$ of Sherman, 2016) and these parameters are present in our data for the POm to M1 projection. In addition, our measurements of terminal size (Fig. 5) indicate a tail of large terminals for this pathway. For these reasons, we conclude that the POm to M1 synapse is class 1. Therefore, the trans-thalamic projection from S1 to M1 appears to be an anatomically and functionally significant sensorimotor pathway that has received little or no attention in our current understanding of sensorimotor processing.

\section{Other possible "drivers" of the trans-thalamic projection} to M1

Class 1 projections between brain areas appear to be associated with feedforward sensory pathways (Sherman, 2016). For the 
POm to M1 projection, all layers showed class 1 properties and the vast majority of M1 cells (91\%) could be activated (Fig. 4). This means that other class 1 projections to POm, not only the S1 layer 5 inputs, could form efficient "driver" information routes to M1. Our anatomical tracing results offer other two candidates to consider: S2 layer 5 and contralateral SpV (Fig. $1 E$ ). We exclude layer 6 cortical inputs because they have shown class 2 modulatory characteristics in all thalamic cells studied thus far (Sherman and Guillery, 2013; Sherman, 2016). The contralateral SpV projection to POm is part of the paralemniscal somatosensory pathway, which weakly influences receptive field properties of the target POm cells (Diamond et al., 1992). This aligns with its classification as a majority class 2 projection ( $71 \%$ of recorded cells), the rest being class 1 (Mo et al., 2017). It is unknown whether the $\mathrm{SpV}$ inputs to M1-projecting POm cells are class 1, class 2, or both. It is also unknown which of these inputs, if any, converge with S1 layer 5 inputs onto the same POm cells. Another possibility for driver inputs to POm to M1 is layer 5 of S2, which innervates with large terminals, suggestive of class 1 inputs (Liao et al., 2010). All layer 5 corticothalamic inputs thus far have also been shown to be class 1 driver projections (Sherman and Guillery, 2013; Sherman, 2016). Based on anatomy, there exists another trans-thalamic pathway: S2 to POm to M1. If true, it seems unlikely that these two trans-thalamic pathways (from S1 layer 5 and S2 layer 5) converge on the same POm cells because S2 layer 5 terminations are found in ventral POm, whereas those from S1 are in dorsal POm (Lévesque et al., 1996; Deschênes et al., 1998; Veinante et al., 2000). In any case, this heretofore unknown but powerful influence of POm on M1 needs to be considered regarding sensorimotor integration.

Potential functional role of the S1 to M1 trans-thalamic pathway Previous work has shown that single whisker-evoked responses in $\mathrm{M} 1$ are completely dependent on S1 activation and this phenomenon was interpreted strictly on the basis of the direct pathway from S1 to M1 (Ferezou et al., 2007). Our results suggest an additional, trans-thalamic pathway that could participate in this process. This raises the question as to the different roles of the direct and trans-thalamic pathways in cortical functioning, a topic discussed previously (Sherman and Guillery, 2013; Sherman, 2016).

It is unlikely that $\mathrm{S} 1$ sends the same information to $\mathrm{M} 1$ via both the direct and trans-thalamic corticocortical routes because the cells of origin of these two routes represent separate populations (Petrof et al., 2012). Furthermore, the layer 5 cells of origin of the trans-thalamic pathways branch extensively to target extrathalamic structures in the brainstem and spinal cord as well as higher-order thalamic relays (Bourassa and Deschênes, 1995; Bourassa et al., 1995; Veinante et al., 2000; Kita and Kita, 2012), whereas the direct projections involve axons without subcorticaldirected branches (Sherman and Guillery, 2013; Sherman, 2016). Therefore, the information passed along the trans-thalamic pathways represents a copy of messages sent to other subcortical centers. Because many of those centers are motor in nature (e.g., the superior colliculus deep layers and various other brainstem nuclei), we have argued that part of the function of these pathways through thalamus is to carry copies of motor commands, or efference copies, to target cortical areas (Sherman and Guillery, 2013; Sherman, 2016). This would mean that the trans-thalamic pathway from S1 to M1 informs M1 of any motor actions possibly initiated by the layer 5 projection cells of S1.

Furthermore, sending efferent copy information from S1 through POm to M1 allows gating of such information, a situa- tion not possible in the direct corticocortical pathway. POm is under powerful GABAergic inhibition by the zona incerta during rest (Trageser and Keller, 2004; Lavallée et al., 2005), but released from this inhibition by M1 projections (Urbain and Deschênes, 2007) or by brainstem cholinergic input (Masri et al., 2006; Trageser et al., 2006). This implies that the information relayed by POm to higher-order cortex is only permitted when necessary (i.e., during active states) and would otherwise remain suppressed.

\section{Conclusions}

We have identified a sensorimotor pathway from primary somatosensory to primary motor cortex through higher order thalamus composed of class 1 glutamatergic synapses, which we have argued underlie the main routes of information processing in sensory systems. This trans-thalamic pathway is therefore likely an essential but underappreciated pathway in sensorimotor processing. The existence of trans-thalamic pathways in general across sensory and now sensorimotor domains suggests that the arrangement of parallel direct and trans-thalamic cortical circuits may be a general feature of cortical functioning, extending the traditional view that higher-order processing is reserved for direct corticocortical circuits.

\section{References}

Agmon A, Connors BW (1991) Thalamocortical responses of mouse somatosensory (barrel) cortex in vitro. Neurosci 41:365-379. CrossRef

Barthó P, Freund TF, Acsády L (2002) Selective GABAergic innervation of thalamic nuclei from zona incerta. Eur J Neurosci 16:999-1014. CrossRef Medline

Beier KT, Steinberg EE, DeLoach KE, Xie S, Miyamichi K, Schwarz L, Gao XJ, Kremer EJ, Malenka RC, Luo L (2015) Circuit architecture of VTA dopamine neurons revealed by systematic input-output mapping. Cell 162: 622-634. CrossRef Medline

Bosman LW, Houweling AR, Owens CB, Tanke N, Shevchouk OT, Rahmati N, Teunissen WH, Ju C, Gong W, Koekkoek SK, De Zeeuw CI (2011) Anatomical pathways involved in generating and sensing rhythmic whisker movements. Front Integr Neurosci 5:53. CrossRef Medline

Bourassa J, Deschênes M (1995) Corticothalamic projections from the primary visual cortex in rats: a single fiber study using biocytin as an anterograde tracer. Neuroscience 66:253-263. CrossRef Medline

Bourassa J, Pinault D, Deschênes M (1995) Corticothalamic projections from the cortical barrel field to the somatosensory thalamus in rats: a single-fibre study using biocytin as an anterograde tracer. Eur J Neurosci 7:19-30. CrossRef Medline

Callaway EM, Luo L (2015) Monosynaptic circuit tracing with glycoproteindeleted rabies viruses. J Neurosci 35:8979-8985. CrossRef Medline

Castro-Alamancos MA, Calcagnotto ME (1999) Presynaptic long-term potentiation in corticothalamic synapses. J Neurosci 19:9090-9097. CrossRef Medline

Cruikshank SJ, Urabe H, Nurmikko AV, Connors BW (2010) Pathwayspecific feedforward circuits between thalamus and neocortex revealed by selective optical stimulation of axons. Neuron 65:230-245. CrossRef Medline

Deschênes M, Veinante P, Zhang ZW (1998) The organization of corticothalamic projections: reciprocity versus parity. Brain Res Rev 28:286-308. CrossRef Medline

Diamond ME, Armstrong-James M, Ebner FF (1992) Somatic sensory responses in the rostral sector of the posterior group (POm) and in the ventral posterior medial nucleus (VPM) of the rat thalamus. J Comp Neurol 318:462-476. CrossRef Medline

Ferezou I, Haiss F, Gentet LJ, Aronoff R, Weber B, Petersen CC (2007) Spatiotemporal dynamics of cortical sensorimotor integration in behaving mice. Neuron 56:907-923. CrossRef Medline

Hooks BM, Mao T, Gutnisky DA, Yamawaki N, Svoboda K, Shepherd GM (2013) Organization of cortical and thalamic input to pyramidal neurons in mouse motor cortex. J Neurosci 33:748-760. CrossRef Medline

Hooks BM, Hires SA, Zhang YX, Huber D, Petreanu L, Svoboda K, Shepherd 
GM (2011) Laminar analysis of excitatory local circuits in vibrissal motor and sensory cortical areas. PLoS Biol 9:e1000572. CrossRef Medline

Hunnicutt BJ, Long BR, Kusefoglu D, Gertz KJ, Zhong H, Mao T (2014) A comprehensive thalamocortical projection map at the mesoscopic level. Nat Neurosci 17:1276-1285. CrossRef Medline

Jackman SL, Beneduce BM, Drew IR, Regehr WG (2014) Achieving highfrequency optical control of synaptic transmission. J Neurosci 34:77047714. CrossRef Medline

Kita T, Kita H (2012) The subthalamic nucleus is one of multiple innervation sites for long-range corticofugal axons: a single-axon tracing study in the rat. J Neurosci 32:5990-5999. CrossRef Medline

Komulainen E, Zdrojewska J, Freemantle E, Mohammad H, Kulesskaya N, Deshpande P, Marchisella F, Mysore R, Hollos P, Michelsen KA, Mågard M, Rauvala H, James P, Coffey ET (2014) JNK1 controls dendritic field size in L2/3 and L5 of the motor cortex, constrains soma size, and influences fine motor coordination. Front Cell Neurosci 8:272. CrossRef Medline

Lam YW, Sherman SM (2011) Functional organization of the thalamic input to the thalamic reticular nucleus. J Neurosci 31:6791-6799. CrossRef Medline

Lavallée P, Urbain N, Dufresne C, Bokor H, Acsády L, Deschênes M (2005) Feedforward inhibitory control of sensory information in higher-order thalamic nuclei. J Neurosci 25:7489-7498. CrossRef Medline

Lévesque M, Gagnon S, Parent A, Deschênes M (1996) Axonal arborizations of corticostriatal and corticothalamic fibers arising from the second somatosensory area in the rat. Cereb Cortex 6:759-770. CrossRef Medline

Li J, Guido W, Bickford ME (2003) Two distinct types of corticothalamic EPSPs and their contribution to short-term synaptic plasticity. J Neurophysiol 90:3429-3440. CrossRef Medline

Liao CC, Chen RF, Lai WS, Lin RC, Yen CT (2010) Distribution of large terminal inputs from the primary and secondary somatosensory cortices to the dorsal thalamus in the rodent. J Comp Neurol 518:2592-2611. CrossRef Medline

Masri R, Trageser JC, Bezdudnaya T, Li Y, Keller A (2006) Cholinergic regulation of the posterior medial thalamic nucleus. J Neurophysiol 96: 2265-2273. CrossRef Medline

Miyamichi K, Shlomai-Fuchs Y, Shu M, Weissbourd BC, Luo L, Mizrahi A (2013) Dissecting local circuits: parvalbumin interneurons underlie broad feedback control of olfactory bulb output. Neuron 80:1232-1245. CrossRef Medline

Miyashita E, Keller A, Asanuma H (1994) input-output organization of the rat vibrissal motor cortex. Exp Brain Res 99:223-232. Medline

Mo C, Petrof I, Viaene AN, Sherman SM (2017) Synaptic properties of the lemniscal and paralemniscal pathways to the mouse somatosensory thalamus. Proc Natl Acad Sci U S A 114:E6212-E6221. CrossRef Medline

Mo C, Sherman SM (2017) A sensorimotor trans-thalamic pathway via higher order thalamus. Soc Neurosci Abstr 43:583.07.

Ohno S, Kuramoto E, Furuta T, Hioki H, Tanaka YR, Fujiyama F, Sonomura T, Uemura M, Sugiyama K, Kaneko T (2012) A morphological analysis of thalamocortical axon fibers of rat posterior thalamic nuclei: a single neuron tracing study with viral vectors. Cereb Cortex 22:2840-2857. CrossRef Medline

Petrof I, Sherman SM (2013) Functional significance of synaptic terminal size in glutamatergic sensory pathways in thalamus and cortex. J Physiol 591:3125-3131. CrossRef Medline

Petrof I, Viaene AN, Sherman SM (2012) Two populations of corticothalamic and interareal corticocortical cells in the subgranular layers of the mouse primary sensory cortices. J Comp Neurol 520:1678-1686. CrossRef Medline

Petrof I, Viaene AN, Sherman SM (2015) Properties of the primary somatosensory cortex projection to the primary motor cortex in the mouse. J Neurophysiol 113:2400-2407. CrossRef Medline

Porter LL, White EL (1983) Afferent and efferent pathways of the vibrissal region of primary motor cortex in the mouse. J Comp Neurol 214:279289. CrossRef Medline

Reardon TR, Murray AJ, Turi GF, Wirblich C, Croce KR, Schnell MJ, Jessell TM, Losonczy A (2016) Rabies virus CVS-N2c(DeltaG) strain enhances retrograde synaptic transfer and neuronal viability. Neuron 89:711-724. CrossRef Medline

Reichova I, Sherman SM (2004) Somatosensory corticothalamic projec- tions: distinguishing drivers from modulators. J Neurophysiol 92:21852197. CrossRef Medline

Rocco MM, Brumberg JC (2007) The sensorimotor slice. J Neurosci Methods 162:139-147. CrossRef Medline

Rocco-Donovan M, Ramos RL, Giraldo S, Brumberg JC (2011) Characteristics of synaptic connections between rodent primary somatosensory and motor cortices. Somatosens Mot Res 28:63-72. CrossRef Medline

Schofield BR (2008) Retrograde axonal tracing with fluorescent markers. Curr Protoc Neurosci. Available at https://doi.org/10.1002/0471142301. ns0117s43.

Schwarz LA, Miyamichi K, Gao XJ, Beier KT, Weissbourd B, DeLoach KE, Ren J, Ibanes S, Malenka RC, Kremer EJ, Luo L (2015) Viral-genetic tracing of the input-output organization of a central noradrenaline circuit. Nature 524:88-92. CrossRef Medline

Sherman SM (2016) Thalamus plays a central role in ongoing cortical functioning. Nat Neurosci 19:533-541. CrossRef Medline

Sherman SM, Guillery RW (2013) Thalamocortical processing: understanding the messages that link the cortex to the world. Cambridge, MA: MIT.

Soudais C, Laplace-Builhe C, Kissa K, Kremer EJ (2001) Preferential transduction of neurons by canine adenovirus vectors and their efficient retrograde transport in vivo. FASEB J 15:2283-2285. CrossRef Medline

Tervo DG, Hwang BY, Viswanathan S, Gaj T, Lavzin M, Ritola KD, Lindo S, Michael S, Kuleshova E, Ojala D, Huang CC, Gerfen CR, Schiller J, Dudman JT, Hantman AW, Looger LL, Schaffer DV, Karpova AY (2016) A designer AAV variant permits efficient retrograde access to projection neurons. Neuron 92:372-382. CrossRef Medline

Theyel BB, Llano DA, Sherman SM (2010) The corticothalamocortical circuit drives higher-order cortex in the mouse. Nat Neurosci 13:84-88. CrossRef Medline

Trageser JC, Keller A (2004) Reducing the uncertainty: gating of peripheral inputs by zona incerta. J Neurosci 24:8911-8915. CrossRef Medline

Trageser JC, Burke KA, Masri R, Li Y, Sellers L, Keller A (2006) Statedependent gating of sensory inputs by zona incerta. J Neurophysiol 96 : 1456-1463. CrossRef Medline

Urbain N, Deschênes M (2007) A new thalamic pathway of vibrissal information modulated by the motor cortex. J Neurosci 27:12407-12412. CrossRef Medline

Vaudano E, Legg CR, Glickstein M (1991) Afferent and efferent connections of temporal association cortex in the rat: a horseradish peroxidase study. Eur J Neurosci 3:317-330. CrossRef Medline

Veinante P, Lavallée P, Deschênes M (2000) Corticothalamic projections from layer 5 of the vibrissal barrel cortex in the rat. J Comp Neurol 424:197-204. CrossRef Medline

Viaene AN, Petrof I, Sherman SM (2011a) Properties of the thalamic projection from the posterior medial nucleus to primary and secondary somatosensory cortices in the mouse. Proc Natl Acad Sci U S A 108:1815618161. CrossRef Medline

Viaene AN, Petrof I, Sherman SM (2011b) Synaptic properties of thalamic input to layers $2 / 3$ in primary somatosensory and auditory cortices. J Neurophysiol 105:279-292. CrossRef Medline

Wall NR, Wickersham IR, Cetin A, De La Parra M, Callaway EM (2010) Monosynaptic circuit tracing in vivo through cre-dependent targeting and complementation of modified rabies virus. Proc Natl Acad Sci U S A 107:21848-21853. CrossRef Medline

Wang Q, Gao E, Burkhalter A (2007) In vivo transcranial imaging of connections in mouse visual cortex. J Neurosci Methods 159:268-276. CrossRef Medline

Wickersham IR, Finke S, Conzelmann KK, Callaway EM (2007) Retrograde neuronal tracing with a deletion-mutant rabies virus. Nat Methods 4:4749. CrossRef Medline

Wu YW, Kim JI, Tawfik VL, Lalchandani RR, Scherrer G, Ding JB (2015) input- and cell-type-specific endocannabinoid-dependent LTD in the striatum. Cell Rep 10:75-87. CrossRef Medline

Yamawaki N, Shepherd GM (2015) Synaptic circuit organization of motor corticothalamic neurons. J Neurosci 35:2293-2307. CrossRef Medline

Yamawaki N, Borges K, Suter BA, Harris KD, Shepherd GM (2014) A genuine layer 4 in motor cortex with prototypical synaptic circuit connectivity. eLife 3:e05422. CrossRef Medline 